\title{
Evolutionary, Cognitive, and Contextual Approaches to the Study of Religious Systems A Proposition of Synthesis
}

\author{
Martin Lang \\ LEVYNA Laboratory for the Experimental Research of Religion, \\ Masaryk University, Czech Republic \\ Department of Human Evolutionary Biology, Harvard University, USA \\ martinlang@mail.muni.cz
}

\author{
Radek Kundt \\ LEVYNA Laboratory for the Experimental Research of Religion, \\ Masaryk University, Czech Republic \\ radek.kundt@gmail.com
}

\begin{abstract}
The explanatory gap between the life sciences and the humanities that is present in the study of human phenomena impedes productive interdisciplinary examination that such a complex subject requires. Manifested as epistemological tensions over reductionism vs. holism, nature vs. nurture, and the study of micro vs. macro context, the divergent research approaches in the humanities and the sciences produce separate bodies of knowledge that are difficult to reconcile. To remedy this incommensurability, the article proposes to employ the complex adaptive systems approach, which allows to study specific cultural systems in their ecologies and to account for the myriads of factors that constitute such systems, including nonlinear interactions between these factors and their evolution. On a specific example of religious systems, we show that by studying cultural systems in their contextual variability, mechanistic composition, and evolutionary history, the humanities and the sciences should be able to fruitfully collaborate while avoiding previous pitfalls of excessive reductionism, genetic determinism, and sweeping overgeneralizations, on the one hand, and pitfalls of excessive holism, cultural determinism, and aversion to any generalizations, on the other hand.
\end{abstract}




\section{Keywords}

cognition - complex adaptive systems - evolution - mechanism - the humanities and the sciences - religion - ritual

\section{Introduction}

Religions are intricately woven into the fabric of cultures across the world, unveiling an astounding variety of beliefs, practices, and institutions that intertwine to create locally salient phenomena influencing the lives of billions. Indeed, religion is an overwhelmingly complex and variable phenomenon. For the study of religions, this complexity warrants an array of disciplines that aim to capture these phenomena from different angles. This has been true since the inception of religious studies as a discipline, as reflected in the classic sociological, psychological, and anthropological works such as those of Durkheim (1912/1964), Freud (1961), and Tylor (1871). However, while these grand theories brought significant scholarly merit to the understanding of religion, their lenses were often focused on restrictive single-cause explanations, thereby preventing the formulation of theories compatible across disciplines.

The issue of encapsulated, mutually incompatible approaches in the study of complex cultural phenomena such as religion is even more pressing if we consider the methodological division between the natural sciences and the humanities (so called Methodenstreit), starting with Dilthey's (1883/1988: 79) famous vision of the human sciences (Geisteswissenschaften). According to Dilthey, the humanities should be theoretically as well as methodologically independent from the natural sciences (Naturwissenschaften). While the sciences should seek explanation (erklären), uncover patterns and laws of the natural world, and provide generalizations and subordinations of these repeating processes to a system of causal connections (similar to what members of the neo-Kantian Baden School conceptualized as nomothetic perspective), the humanities should seek understanding (verstehen) of unique events, describing and interpreting the world of human inner experience, which is largely seen as free from causal necessity (similar to the Baden School's concept of idiographic perspective). Since religion (and culture in general) was increasingly viewed as a subject of the humanities and religious scholars embraced Dilthey's vision of the humanities, the study of religion gradually diverged from the opportunity to harness scientific approaches and encapsulated itself as immune to scientific explanations. 
Thus, when the life sciences initially entered into the study of religion, the seemingly different epistemological dimension of their approach led scientists to ignore decades of research within the humanities and to search for oversimplified explanations of religious phenomena. By proposing reductive explanations, such as "the God gene" (Hamer 2005) or "the God module" in the brain (Albright 2000), the sciences brought a competing framework that was radically incompatible with the interpretative framework in the humanities, thus echoing the old Methodenstreit (Wiebe 2019: 130-138). While the simplistic approaches in the life sciences were subsequently dismissed by the scientific community (e.g., Geertz 2008: 9-12; Schjoedt 2009: 316-318), and new research focused on the study of brain mechanisms related only to very specific religious phenomena (Inzlicht, McGregor, Hirsh, \& Nash 2009; Schjoedt, Stødkilde-Jørgensen, Geertz, \& Roepstorff 2009), the explanatory framework of life sciences remains incompatible with most approaches typical for the humanities. Contrary to some incompatibilities among disciplines within the humanities (e.g., Tylor's individualist and intellectualist approach vs. Durkheim's collectivist and emotionalist approach), the sciences bring a suite of ontologi$\mathrm{cal}$ and epistemological assumptions that divide disciplines studying religion cross-sectionally, producing tremendous volumes of mutually incompatible theories of religion.

Coined as the "two cultures" problem, the incommensurability of the humanities and sciences in the study of cultural phenomena has long since been recognized (Snow 1961). In this paper, we propose a framework that could remedy some of the tensions between the two cultures and that should lead to theories of cultural phenomena that might be compatible across disciplines. To begin, we identify three main points of tension between the sciences and the humanities, which to a large extent are mutually intertwined and selfpropelling. These issues are laid out in a simplified manner as we encounter them in discussions with our colleagues who study religion.

First, scholars in the life sciences programmatically use reduction to decompose studied phenomena into their building blocks (Asprem \& Taves 2018; Taves 2010) that can be described by lower-level disciplines and afford simpler explanations of higher-level phenomena (Schaffner 1967: 114; Slingerland 2008b: 387-392). However, scholars in the humanities often interject that cultural phenomena cannot be decomposed and must be understood within their context (C. Geertz 1973: 10-13) and/or in their whole, which is not reducible to other elements (or even to non-religious elements as conceptualized by various strains of phenomenology, e.g., Otto 1936: 7). This tension is especially aggravated by reductionist propositions such as from scholars in the New 
Wave Reductionism camp (Bickle 2003) who claim that lower-level sciences should replace the humanities and social sciences because all phenomena can be explained by reference to their material underpinnings (i.e., studying religions only via neuroscientific methodology). Admittedly, the New Wave Reductionism is on the extreme side of the reductionist spectrum, and such propositions are problematic not only for the humanities/social sciences but for the scientific approach in general. However, even the milder forms of reductionism, which suggest that scholars can decompose a phenomenon into its building blocks and use a simpler explanatory framework to subsequently arrive at a composite explanation of the phenomenon (e.g., psychological mechanisms facilitating the perception of supernatural agents), is foreign to many in the humanities.

Scholars in the humanities often interject that phenomena such as religion cannot be explained via the building-blocks approach because it does not allow us to capture the full complexity of the phenomenon as a whole (Cho \& Squier 2008: 434-443; Shweder 2011: 60-62). That is, phenomenon X cannot be reduced to a set of statements $\mathrm{Y}$ that would be logically equivalent to $\mathrm{X}$ (as classical reductionism would have it; Nagel 1961), because of the impossibility to specify all $\mathrm{Y}$ statements in necessary detail. As a consequence, the method of reduction that would facilitate connection to scientific disciplines is often dismissed in the humanities as inefficient (scholars can capture only banal laws), if not downright futile. The aversion to using lower-level building blocks in studying complex phenomena is often expressed in sayings such as 'one does not shoot sparrows with a canon' or that 'aerodynamic force cannot explain the variation in aircraft styles'. The implications of these sayings are that reduction is too blunt/rough a tool for refined problems (similar to 'using a sledgehammer to crack a nut' problem) and does not bring any explanatory leverage because lower-level laws are too crude and therefore banal for complex higher-level phenomena. Indeed, all aircraft styles need to conform to the aerodynamic force, but extra theories are needed to account for the variation in aircraft styles.

Second, reducing cultural diversity into general patterns even within a single discipline is often seen as discarding the "thick" variability humanistic scholars study in the first place (C. Geertz 1973: 3-32). Generalizing accounts that sweep cross-cultural and cross-historic variability often oversimplify important differences on the micro level and draw false conclusions based on the lack of insight into specific particularities of different contexts on the macro level. Indeed, any grand theory will always encounter plentiful counter examples that do not exactly fit its predictions. Consequently, grand theories explaining religions, religiosity, and religious behavior were abandoned, and 
religious scholars have started to specialize in the study of specific traditions and symbolical systems, often embedding this particular knowledge in their discipline-specific interpretative frameworks (Ambasciano 2016: 148-150). The rejection of "grand narratives" in the history of religious studies is, at least partially, a resistance to the past tendency to bend the micro-contexts to fit into the greater schema or to cherry-pick only specific examples (Slingerland \& Sullivan 2017: 314-315).

At the extreme position, scholars in the humanities resigned from making any generalizations at all and have started to create "maps" of the territory in a one-to-one scale (J. Z. Smith 1991), essentially arguing that anything else would be short of the humanist ideal (C. Geertz 1983: 232-234). That which was at first studied as a case consisting of an aggregation of many underlying phenomena (e.g., the Battle of White Mountain as a type of 17 th century warring clash, as a type of armed power struggle, etc.) became studied as a unique phenomenon on its own. Note that this position is far more extreme than just acknowledging the uniqueness of any spatially and temporarily occurring phenomena, which are all unrepeatable in their complexity (except for some purely theoretical accounts). Proponents of the "territory approach" posit that nothing we learn about the phenomenon can be used in our knowledge about any other phenomena, resigning on the general categorization of events. This position is in sharp contrast with the scientific approach in that it forgoes the foundational idea of creating and testing simplified models of the complex world.

Third, even for scholars in the social sciences who embrace generalizing and quantitative approaches, the gap between the life sciences and the humanities rears its ugly head in the form of disagreements on the determinants of human behavior. Whereas scholars in the life sciences usually stress the role of ecological factors and genetic predispositions in behavior, scholars in the humanities put the emphasis on nurture; that is, on the learning of social roles and norms that determine individual behavior within a specific social and cultural context (Carroll, et al., 2017). While humanistic scholars do not deny that people are born with biological predispositions, these predispositions are usually reduced to primitive instincts and reflexes that are equivalent for all humans (for a criticism of this approach, see Tooby \& Cosmides 1992). Likewise, the ecological factors such as climate are rarely considered. If genetic and environmental factors cannot explain the ample inter- and intra-group cultural variability, the variability has to stem from social learning. By stressing the importance of nurture (vs. nature), "nurturists" see the mind as a contentfree processing device that is organized by socially constructed worlds (Berger \& Luckmann 1991). The life sciences, on the other hand, investigate in-born 
predispositions and different rates of genetic expressions and their influence on human behavior in natural environments. While these natural predispositions cannot fully explain cultural diversity, they point to shared patterns underlying human behavior in specific contexts.

Amidst the clash between the genetic and cultural determinism of human behavior appears another related point of tension, namely how much humans behave in deterministic patterns at all. In the sciences, individual agency is seen as either relatively unimportant due to its small effects or subordinate within the causal system (and as such, more or less derivable). In the humanities, on the other hand, individual agency is seen as playing a pivotal role in the studied phenomena, and agency is sometimes even considered to be free from any causal rule (Dilthey 1883/1988: 79 ). While this is an extreme position, most scholars in the humanities would probably agree that the humanities should particularly study inner motives and conscious intentions as drivers of human behavior, seeing those factors not only as independent from external forces but also as main factors shaping the phenomena of interest. ${ }^{1}$ This position, in turn, extends to the study of meanings that actors ascribe to their actions, ignoring any deeper patterns possibly driving human behavior.

In summary, the problem that this paper addresses is the increasing specialization of academic disciplines and their encapsulation, leading to mutually exclusive approaches to the study of complex cultural phenomena such as religion, manifested in the simplifying labels of "humanities" and "sciences". While this situation illustrates the multi-disciplinary nature of the study of religion dictated by the complexity of its object, the lack of cross-talk between disciplines significantly hinders advancements in the scholarly understanding of religion. Maintaining the incommensurability of the scientific and humanistic perspectives only further propagates the gap and leads to exponentially diverging research trajectories manifested as a growing volume of competing theories. This is not to say that competing theories are not desired in academia, quite the contrary. However, if the competitiveness arises from metaphysical

1 For example, a model of mate guarding strategies of male chimpanzees (Pan troglodytes) and their dependency on sex ratios in a given population does not account for motivations, beliefs, and desires of individual chimpanzees. Ignoring individual chimpanzee agency does not usually upset anyone; however, when studying humans, individual agency suddenly matters above anything else. The problem is not how much space for agency should be allowed in what models of which species; rather, the problem is why some humanists feel so strongly that when considering humans, every model, including, for example, the broad dependency of human mate guarding strategies on environmental pressures, should be based mainly and primarily on individual motivations, beliefs, and desires. 
disagreements rather than testable theories (Dupré 1996), research progress is not warranted. The consistency of theories should be the default principle of building knowledge (Slingerland \& Bulbulia 2011: 310), and, therefore, finding the ways to bridge disparate academic approaches should be of great interest to scholars striving for progress in the study of religion.

Importantly, theories integrating diverse scholarly perspectives on, for instance, religion could afford a complex understanding of the studied phenomenon. Instead of studying evolutionary, cognitive, and contextual layers separately, joining them into one research program can prove fertile for all three lines of research. Mutual inspiration and corroboration of theories are the main perks potentially gained by this fusion. While the thick layer of contextual observation, description, and interpretation may inspire questions about the structure and function of the human mind, the evolutionary and mechanistically focused scholars can offer new insights into particular events based on underlying physiological, neuro-cognitive, and psychological processes. Furthermore, theorizing about the joint workings of various evolved cognitive mechanisms in a specific context can spark a cascade of selfcorrecting refinements by giving scholars the opportunity to compare their theories against theories from different disciplines. Without the willingness to cross the middle point between the "two cultures", however, research programs on complex cultural phenomena such as religion will suffer from the disparity of fragmentary approaches manifested as an emphasis on wholeness, microlevel, and nurture on the one hand, and reduction, generalization, and nature on the other hand.

Here, we illustrate the principles of integration on the subject that we study, that is, religion and follow the appeal from various scholars of religion for tighter integration of the humanities and sciences (Ambasciano 2016; Asprem \& Taves 2018; Bulbulia \& Slingerland 2012; Martin \& Wiebe 2019; Petersen, Gilhus, Martin, Jensen, \& Soerensen 2019; Slingerland 2008a; Slingerland \& Collard 2011; Taves 2011). We introduce a refined model that is not a forced choice between losing a precious contextuality or losing a possibility to generalize but tries to give due credit to both. Following previous proposals of vertical integration (Tooby \& Cosmides 1992) and second-wave consilience (Slingerland \& Collard 2011), we introduce a three-dimensional integration of academic disciplines in a Euclidian space based on three coordinates: the width, height, and depth (as an extension of the $1 \mathrm{D}$ vertical integration). ${ }^{2}$ The paths to such ${ }_{3} \mathrm{D}$ integration, which would ameliorate the three points of tensions between the sciences and the humanities, are described in the next section.

2 For a similar yet distinct argument, see also Petersen's concept of Continuity (Petersen 2019). 
In 1998, Edward O. Wilson published a highly influential and controversial book called Consilience: The Unity of Knowledge, where he argued that consilience is the most important scientific endeavor. For Wilson, consilience is "the linking of facts and fact-based theory across disciplines to create a common groundwork of explanation" (8). Good explanations, according to Wilson, are those that are consistent with each other, and scientists should be careful to align their explanations with the causality principles of disciplines on lower explanatory levels (58-60). Assuming the hierarchical division of academic disciplines postulated by Aristotle and later elaborated by the French encyclopedists, one should be able to move smoothly from the highest-level disciplines to the lowest-level ones. Indeed, this is what Wilson showed in his study of ant distress communication, first investigating ant glands physiologically, then analyzing their chemical composition, and finally offering the mathematical model of their transmission.

However, with the growing complexity of the phenomena studied, the consilient approach will start reaching its limits because the current level of knowledge does not allow one to jump from an observation of a particular cultural event to, for instance, a detailed neuroscientific description of this event. Wilson's consilient approach demonstrated on ant behavior will hardly be sufficient to address the three issues delineated in the introduction. First, a crucial step in the ant example was the reduction of the studied phenomenon (distress communication) into a lower-level element (chemical substance), a step that humanistic scholars are reluctant to take. Second, the example is illfitted to human phenomena since ants most likely do not exhibit any cultural transmission; hence, the distinction between nature and nurture is heavily skewed toward nature. Finally, the strong emphasis on nature precludes the study of individual ants/ant groups, since the explanations put forward by Wilson should apply to all members of the studied species, skewing the study toward general patterns and ignoring individual ant agency.

While putting forward a programmatic example, the consilient model fails to take into account the complexity of human phenomena by overly relying on the scientific principles that were developed to study matters of lower complexity. Nevertheless, the basic idea of the consilient approach is, in our view, inherently correct. We believe that real progress in the study of human cultures can be made by using the principles of the scientific methodology such as creating simplified models of the complex world and testing these models against data. Hypotheses testing has so far proven to be the best way for gradually acquiring knowledge, subjecting scholars to the need for 
an evaluation of their conjectures against data (Slingerland \& Collard 2011: 19-22). Of course, the more complex phenomena scholars would like to capture with their models, the less precise and "stupider" (Smaldino 2017) these models will be. At its extreme, modeling individual behavior in a specific spatio-temporal context will be almost impossible, seemingly giving justice to humanistic reluctance to modeling. However, by and large, we believe that modeling and hypotheses testing will be useful in most cases. Models well informed by observations, be it ethnography, the study of primary sources or archaeological records should convene to both humanistic emphasis on contextual variability and scientific desire for explanatory power. Nonetheless, the question remains of how can we build testable models of complex cultural phenomena that would appease and give proper credit to both the humanistic and scientific approaches?

To overcome the issues in integration created by the complexity of humanrelated phenomena, we suggest that the systemic approach is an essential starting point for any such endeavor. We advocate the thesis that understanding religions as complex adaptive systems may help overcome, at least to some extent, the issues dividing scholars who are anchored betwixt disciplinary boundaries. The science of complex systems appears well-fitted to this problem because the science itself has been highly interdisciplinary since its birth. ${ }^{3}$ So, what are complex adaptive systems? Decomposing the term into its constitutive elements, systems can be understood as structures of interrelated components that have a specific goal or function. For any system to work, it needs an energy inflow, which is then processed through the system and transformed into the system's output. For example, the human immune system comprises (among other elements) bone marrow, white blood cells, the thymus, the spleen, lymph nodes, etc. These elements are combined such as to detect and discard pathogens and fueled by micro- and macronutrient input. If we add the adjective adaptive to a system, it means that the function of this system bears an evolutionary advantage for the system or for the larger system that the studied system is part of (e.g., the immune system within the human body is an adaptive response to threatening infections). Furthermore, the adaptive component also implies change-the system changes and adapts to its changing environment (new viruses). The

3 Complexity science connected developments in mathematics such as the theory of non-linear dynamical systems and the study of deterministic chaos, the principle of selforganization studied within thermodynamics, feedback-loops studied in cybernetics and systems science applied in anthropology, sociology, and economy. Adding the evolutionary dimension to complex systems, biologists and geneticists applied the principles of complex systems to living organisms and their adaptive change over time. 
term complex implies a system with many parts that interact in a non-linear fashion. Often contrasted with complicated systems, in which many parts are linearly additive, the behavior of complex systems emerges from the nonlinear interactions among its parts and is described as deterministic chaos. That is, the behavior on the aggregate level of the system is crucially dependent on the initial conditions, and even small changes may yield unpredictable changes (as opposed to complicated systems where a small change in initial conditions translates into a small change on the system's aggregate level). For instance, within the immune system, many different cells and hundreds of chemicals nonlinearly interact and while medicine significantly advanced the treatment of malfunctioning immune systems, its perfect mastery is, at the moment, far from possible.

This basic delineation of complex adaptive systems has several interesting consequences for the three issues discussed in this paper. ${ }^{4}$ First, as opposed to complicated systems, decomposing complex systems into its building blocks may severely hamper the understanding of the system as a whole. Due to the non-linear interactions (such as feedback loops and oscillations) between a system's many components, the observed aggregate behavior is emergent, often described by the phrase "the whole is more than the sum of its parts". That is, the non-linearity of interactions prohibits putting forward simplistic additive explanations of the whole system because such explanations will rarely resemble the phenomenon under study. The principle of emergence is sympathetic to the humanistic reluctance to reduction because it recognizes the difficulty of finding simple lower-level explanations for complex phenomena. However, emergence does not necessarily imply that scholars are not able to study a system's constitutive elements in isolation. On the contrary, the emergent approach recognizes that studying a system's building blocks in isolation is fruitful for understanding their function; but to account for the emergent properties of the system as a whole, scholars need to study how the composition and organization of individual elements give rise to the functioning of the whole system (rather than selecting only one part to explain the system's workings).

Second, understanding systems as dynamically adaptive allows scholars to account for their change and, most importantly, for the feedback loops between the aggregate-level behavior and the constitutive elements. Translated to the nature vs. nurture debate, the combination of genetic and cultural

4 For additional characteristics of complex adaptive systems and their application to religious systems, see Sosis (2017) and Sosis (2019a, b). 
building blocks give rise to individual behaviors that on the aggregate level of society create religious phenomena, which, in turn, influence both individual fitness and social conditions, that is, the genetic as well as cultural building blocks. Finally, the integration of the nonlinearity and evolution principles implies that individual systems will be path-dependent, that is, their current state will crucially depend on its history that may, to some extent, be driven by stochasticity. Since random fluctuations might be amplified through nonlinear interactions, the system may end up in an unpredictable state. Hence, while studying macro-level patterns may help scholars to understand a system's behavior to a large extent, there will be specificities and idiosyncrasies at the micro-level that would be unpredictable from generalized rules (giving space for individual agency).

The most elaborate application of the complex adaptive systems theory on religious phenomena yet has been put forward by Richard Sosis $(2017,2019 a$, $2019 \mathrm{~b}$ ). Sosis created a general template of religious systems, arguing that these systems comprise eight basic elements that are essential for their functioning: ritual, taboo, authority, myth, sacred, supernatural agent, moral obligation, and meaning. ${ }^{5}$ Ritual is one of the most crucial elements because, through ritual, energy in terms of caloric expenditure enters into the system and through interactions between the system's elements creates the resulting outputs of the system on coordinated and cooperative behavior, health, and reproduction of a community's members. If these impacts are positive, the system is adaptive and able to harness energy from the environment (e.g., in the form of calories), attracting and producing new members. If the religious system has negative impacts, it will die out or transform the content of the eight elements through revitalization movements. For example, a Shaker community living in 19th-century New England was a religious system that comprised all the basic eight elements and was supported by the energy pushed to the system through Shaker rituals, creating a specific Shaker environment. However, since the content of these eight elements were highly maladaptive-procreation was taboo- the energy inflow through ritual gradually ceded and the system disintegrated.

5 While selecting "only" eight elements may seem as extremely reductive (and definitely is reductive), the interactions of these elements may result in a wide array of religious systems. Using Holland's example with face recognition (Holland 1992: 22), if each of these eight elements of religious systems would have ten variations, we would get $8^{10}$ possible systems, that is, 1073741824 possible religious systems. 
Returning to the issue of this paper, Sosis selects eight building blocks to define religious systems ${ }^{6}$ but argues that these blocks interact in a nonlinear fashion and feedback loops. For example, ritual performance may legitimize belief in a certain supernatural agent, which, in turn, may reinforce ritual performance ("god demands rituals") through a positive feedback loop. Thus, taking any of these elements out of the system would destroy the understanding of the system's aggregate-level behavior and its effects on cooperation, health, and reproduction. This approach also recognizes the need for interpreting the relationship between individual building blocks on the level of those blocks, without the need to reduce these blocks into their lower-level components (for example, the relationship between specific taboo and its mythological legitimization). However, this does not imply that building blocks of religious systems are autonomous or sui generis (Otto 1936: 7) —each block should be, in principle, decomposable into many lower-level blocks; and the lower-level blocks serve specific functions within the system and have their own evolutionary history.

To account for the adaptive nature of complex systems, it is important to study the potential adaptive functions on the aggregate level of complex systems, that is, on the level of the building-blocks coalescence. While individual blocks of religious systems have their specific functions, which can be studied by using the method of reduction, the adaptive functions can be studied only at the level of the whole system and the socio-ecological environments it creates (respecting emergence). Moreover, the fact that such systems are adaptive also means that these systems have history and are dynamically changing in response to ecological pressures (systems evolve). ${ }^{7}$ The feed-back loop principle, which is characteristic of complex adaptive systems, recognizes that religious systems are flexible enough to vary the content but also the configuration of the basic building blocks over the course of evolution. The inability of

6 For other building blocks, see, for instance, Smart (1996).

7 At this point, it may be appropriate to mention the unfortunate history of evolutionary approaches to religion and the fact that the complex adaptive systems approach is markedly different from the theories of early cultural evolutionists such as J. Lubbock, E. B. Tylor, W. R. Smith, and R. R. Marrett. To the best of their knowledge, these scholars attempted to explain the process of human intellectual evolution. However, rather than succeeding in applying the blind and mechanical Darwinian principles of natural selection to the process of human evolution, they ended up linking human evolution with value-based concepts of progress (Kundt 2015: 11-32). This approach led to fallacies by mixing evolutionary processes with teleology/directionality, rigid unilinearity or overusing unverifiable just-so stories. Instead, the complex adaptive systems approach embraces the principles of neo-Darwinian synthesis in the study of human evolution, which affords methodological advancements that avoid previous pitfalls. 
a particular religious system to adapt to changing ecological pressures would lead to a reduced input of energy through ritual performance, and the system would no longer function (directly impacting biological fitness). Thus, the evolving religious environments scaffolded by the elements of religious systems have direct impact on human behavior and its adaptive nature.

The complex adaptive systems approach also highlights the amplification of random fluctuations in a system's development (history). Sosis (2019b) describes that through his fieldwork, he visited different Jewish communities across the globe, noting their differences in language, clothing, food preferences, and prayer styles. He notes that these differences may be a result of the adaptation of these various religious systems (Jewish communities) to a concrete ecological context; however, the establishment of a Jewish community at a particular place might have been to some extent influenced by random factors such as winds directing ships to specific areas. Hence, the actual microstate of particular communities might be best studied as resulting from the amplification of these random factors (we encourage readers to engage with Sosis' writings on this topic for a fuller argument).

The fact that the composition of a specific system depends on the system's history and ecological conditions offers another important insight into the definitional problems that plague religious studies (and similar humanistic disciplines) for decades. Indeed, selecting universal building blocks of a system would be extremely difficulty because each system will more or less deviate due to its historical circumstances, stochasticity, and the specific function it fulfills in its environment. Sosis puts forward a universal model of religious systems comprising eight building blocks but argues that the composition and mostly the content of systems will vary by socio-ecological conditions; hence, rather than being a setback in the study of religion, the definitional problems can be understood and explained via the complex adaptive systems framework. In other words, this approach offers researchers definitional flexibility as long as the researchers would be able to demonstrate the studied function of the system at the level of a system's blocks delineation.

For example, in some societies, a religious system may comprise the eight blocks defined by Sosis and be easily distinguishable from other cultural complex systems such as labor market or kinship system. In such cases, researchers should be able to demonstrate the effect of religious systems on, for instance, the cooperative and coordinated outputs, which are largely independent of the other systems. In other societies, however, kinship and religious systems might be indistinguishable and form one inter-linked system affecting cooperative behaviors. The expression 'religious system' might thus not be apt for each studied phenomenon that includes some of the building blocks 
delineated by Sosis; however, we should stress that more often than not, religious systems should be identifiable due to their important and specific function (i.e., specific in comparison with other systems) that they play in their environments. Analogically, the immune system interacts with other systems within the human body and can be thus considered artificially isolated from the wholeness of the human body; but this artificiality of isolation does not preclude researchers to study the immune system's workings and specific functions (Sosis 2017: 220-221).

Together, the complex adaptive systems approach allows scholars to study general patterns while appreciating local specificities and historical dependencies, which are not predictable from the general patterns. Furthermore, this approach also appreciates the need for the study of the aggregate-level behavior rather than reduction. However, and this is a crucial point, it allows for reduction, given that reduction is done in the most careful and precise ways as to give proper considerations for the nonlinear interactions between the system's building blocks. In other words, scholars can decompose systems (including those commonly defined as religious), which function at a grouplevel, into subsystems and mechanisms that are carried by individual cognitive and emotional mechanisms, predisposed by the human genome. The complex adaptive systems approach allows for the nestedness and hierarchy of systems and their mutual interactions, which can be studied across various disciplines-from population genetics, over neuroscience, to cognitive and psychological sciences.

This implication leads to the main point of this paper-that we should be able to study religious systems (and other cultural systems) by decomposing them vertically into subsystems and mechanisms while tracking their historical and evolutionary change (including the change in their mechanisms) with full appreciation for the systems' and subsystems' differences that result from stochasticity and the adaptation to local specificities. That is to say, we should study systems in three dimensions: mechanistic height that would decompose phenomena into their building blocks, mapping their nonlinear interconnectedness; evolutionary depth that would track the adaptive features of studied phenomena and their change; and contextual width that would study local forces, including micro-historical events and individual behavior on the most fine-grained level. See Figure 1 for a three-dimensional schematic of the proposed model. In the following sections, we examine each of the three dimensions in more detail, highlight previous research, and suggest ways these dimensions can be elaborated in future research. Finally, we provide a synthetic example of the $3 \mathrm{D}$ integration. 


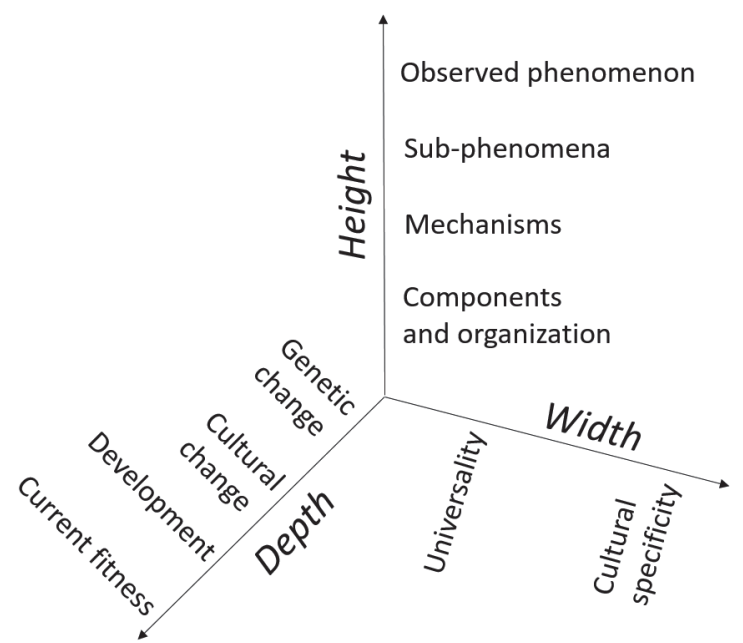

FIGURE 1 A three-dimensional representation of research strategies accentuating different levels of studied phenomena. The height axis represents phenomenal and mechanistic decomposition, highlighting the level of reduction of the studied phenomenon. The width axis concerns moving from general cultural patterns to specific cultural phenomena, positing research on the macro-micro scale. The depth axis regards evolutionary and historical analyses, with the assessment of the biological fitness of the observed phenomena.

\section{II $\quad 3^{D}$ Integration}

\section{A Mechanistic Height}

The discussion of the complex systems approach together with the entire idea of building scientific models needs to start with the discussion of reduction, which is inherently connected to the height dimension (although in its various forms, the problem of reduction also applies to the nature vs. nurture and micro vs. macro issues). We argued in previous sections that any complex phenomenon should be, in principle, decomposable into its building blocks. However, this decomposition comes with a price and is not always feasible, given that individual spatio-temporal events could be decomposed into billions of factors that may play a role in understanding that event. Hence, at any given time, scholars need to reduce the number of factors that are considered 
when investigating a particular phenomenon. The need for reduction has three important consequences for the integrative approach. First, each description, theory, or explanation is reductive, omitting some factors while highlighting others (Slingerland 2008b: 384); which means that it will never be possible to integrate all factors in the three dimensions (as Laplace's demon might have it). Second, choosing which factors are important for a particular phenomenon is the point of tension between the humanities and the sciences, with disagreements on the number of necessary factors, their explanatory level, and explanatory power. Third, even when accepting the need for reduction, decomposing a phenomenon into factors that give rise to this phenomenon will not be able to account for emerging properties on the top level of the phenomenon. We first explain the necessity of reduction and then suggest ways to deal with the problem of selecting factors and accounting for the phenomenon's emergent properties.

When describing and/or explaining a phenomenon, any academic work is necessarily reductive because no human being can fully encompass a particular situation, not to mention that such a description would probably be endlessly boring. For example, a historical study of the inception of the Protestant movement might focus on Martin Luther's decision to write the Disputation on the Power and Efficacy of Indulgences, trying to illuminate the factors leading Luther to formulate such theses. However, no self-respecting historian of religion would ask what Luther ate for breakfast before (allegedly) nailing the 95 theses to the door of Wittenberg Castle church. These factors are either not known or considered irrelevant. But what if the ill-cooked breakfast upset Luther such that he chose a more violent form of presentation of the 95 theses (instead of, e.g., reciting to a local philosophy circle) that later revolutionized the Christian world? Are we not missing a crucial piece of the puzzle by reducing the historical event into the study of Luther's intellectual predecessors and his upbringing?

The complex adaptive systems approach offers a solution to this problem by explicitly acknowledging and advocating the factors that are important for a system's functioning. Had avian influenza been a possible source of disease in Luther's time, the fact that he loved poultry might have been part of the model explaining the spread of the Protestant movement. Of course, this is a ridiculous example, but its purpose is to illustrate that even factors that some scholars consider irrelevant might have its relevance in the model, given that there is a sound rationale for including them. Put differently, the principle of decomposition inherent in the complex adaptive systems approach may in fact be able to capture a phenomenon in its fullness better than other descriptions because it allows for seemingly "unimportant" factors to be plugged into 
the model and to be given weight in influencing the resulting phenomenon. Moreover, the weight of a specific factor might be modeled and experimentally tested, improving the estimates of the factors composing the studied complex adaptive system (rather than only speculated on).

Given the assumption that we must reductively select factors, we are left with questions about the number, explanatory level, and explanatory power of the selected factors. Returning to the avian influenza and Luther's fondness of poultry, arguing that a viral pandemic is the main driver behind the restructuralization of any religious system would be a good example of the classic pitfall that is responsible for the negative connotations of the word reduction. Using a single, lower-level factor to explain a phenomenon on a higher-level is problematic because it misses many important factors. Moreover, skipping too many explanatory levels leads to low-level explanations being necessarily banal, as illustrated with the explanatory power of the aerodynamic force when trying to account for the variation in aircraft styles. Such simplified reductions to lower-level factors severely impede the principle of vertical integration. Thus, for the truly integrative approach, we need a reductive principle that would appreciate the fact that the higher the explanatory level, the more interacting components the phenomenon would comprise. We suggest that the principle of emergence as conceptualized in Bechtel's mechanistic approach (Bechtel 2008, 2011; Bechtel \& Richardson 2010) may hold the solution that is compatible with the complex adaptive systems approach.

Bechtel's mechanistic analysis disassembles a phenomenon into its constitutive parts but, crucially, recognizes that researchers also need to consider the organizational principles of individual parts (Bechtel \& Abrahamsen 2010: $322-323)$. That is, it is not enough to just select the building blocks of a phenomenon; the mechanistic approach should specify functional relationships between these building blocks. In this specification, reduction does not mean only correlating a higher-level phenomenon with, say, neuronal activations. Correlational approaches can highlight the parts of the mechanism employed in the emerging phenomenon; however, it is the specific organization of the parts of the mechanism that needs to be described in order to understand the mechanism's operations. The emergent properties are given by the organizational structure, which is not implied by individual components. This is especially important when dealing with mechanisms that do not have a linear composition but involve non-linear organizational features such as negative feedback loops or oscillations (Bechtel 2011: 539-541; see Bechtel \& Abrahamsen 2010 for an example of oscillaitons in circadian rythyms). Indeed, these organizational features are what give higher-level phenomena their emerging properties. 
Furthermore, the principle of emergence, as conceptualized in this mechanistic approach, recognizes that phenomena have a unique organization on each complexity level, and that this organization cannot be predicted from lower levels (Mitchell 2009: 109-110). Note that in this specification, the meaning of "higher level" is relative: it can be the visual cortex relative to its neuronal substructures or human sensory system relative to vision, olfaction, etc. Thus, the principle of mechanistic organization implies that higher-level phenomena should be more complex, consisting of more hierarchically nested mechanisms. Importantly, while mechanisms may have their own specific functions, they can also be part of a more complex mechanism that realizes a phenomenon on yet a higher level of complexity. For example, neurons mediating vision are composed of mechanistically functioning nuclei, mitochondria, cytoplasm, which are themselves composed of yet other mechanistically functioning elements. ${ }^{8}$

Responsibly investigating high-level phenomena using the mechanistic approach means decomposing the phenomena into sub-phenomena, which, in turn, can be decomposed into mechanisms, mapping their components and their operations at particular levels. For example, anxiety decrease after performing a specific ritual (e.g., the Lord's Prayer) can be considered as a phenomenon at the top of the studied mechanistic hierarchy (as hypothesized by, for instance, Malinowski 1948; and Sosis \& Handwerker 2011). The anxiety alleviation can be assumed to be mediated by less complex phenomena such as compulsion, behavioral rigidity and repetitiveness, or working memory overload (Eilam 2006; Lang, Krátký, Shaver, Jerotijević, \& Xygalatas 2015; Liénard \& Boyer 2006). These phenomena can be further decomposed into lower-level mechanisms. In the case of compulsion, for instance, these mechanisms can include adrenaline and noradrenaline release, increased heart rate and breathing rate, etc. Working memory overload can be decomposed into pupillary dilation, increased sympathetic activation, or hyperactivity in the prefrontal cortex and parietal areas. Importantly, these mechanisms do not work in isolation but create a system of interconnected feedback loops, whereas anxiety might be triggered by some sensory input, elevating heart rate and stress hormones that, in turn, prompt ritual behavior, which de-regulates the high levels of stress hormones and decreases perceived anxiety (Lang 2018). Thus, scholars can analyze the dynamic relationship between anxiety and ritual on many

8 See Bechtel 2008, Chapters 2-3 for examples of the phenomenal decomposition of memory and mechanistic decomposition of vision. 
levels that mutually interact, be it conscious perception or neurohormonal mechanisms. ${ }^{9}$

In summary, the mechanistic approach allows scholars to connect different levels of emergent complexity by decomposing both phenomena and mechanisms into components hypothesized under heuristic identity and by reconstructing their organized operations. Importantly, an experimental approach employing statistical testing may help decide which factors are truly important for a given phenomenon and what is the factor's explanatory power. The possibility to incorporate various components into the reconstruction of mechanistic operations gives scholars considerable flexibility when choosing between a mechanism's universality ("the backbone" working across different contexts) and specificity (including peculiar components important in a specific context). When deciding between universality and specificity, scholars need to account for the costs and benefits of these two modeling strategies and determine whether their models are sufficiently flexible to address contextual variability, yet also sufficiently general to have good explanatory power.

\section{B Contextual Width}

Research along this dimension is pulled between claims of universal or general patterns of religious phenomena on one of the extremes, and the emphasis on exceptionality and unrepeatability of particular spatio-temporal cases on the other extreme. On the one hand, the reliance on the Diltheyian conception of Geisteswissenschaften and the "territorial approach", which argues that scholars in the humanities study exceptional and sole cases, has precluded many scholars from viewing events as part of larger evolutionary processes. Understanding the study of religious phenomena as the study of incomparable individual events severely limits the potential of greater understanding of humanity. On the other hand, sweeping over-generalizations built on cherrypicked data, which are too often symptomatic for macro-analyses, ignore contextual variability and lead to unfounded claims detached from reality. To overcome this polarization, we argue that complex adaptive systems should be analyzed through meticulous work on the micro level, from which it should be possible to extrapolate on the macro level.

9 A potential obstacle for this approach is the need for intertheoretic translations. To remedy this issue, the theory of explanatory pluralism (McCauley 2009; McCauley \& Bechtel 2001) emphasizes that theories should be developed jointly on different explanatory levels. To facilitate translations from one level to another, McCauley and Bechtel (2001) proposed the concept of heuristic identities that can function across different levels of scientific investigation. 
Indeed, there is much to be gained from dissecting spatio-temporal cultural context into smaller elements and from studying these elements in full detail, as illustrated in the classical studies of the Zande by Evans-Pritchard (1956), of the Maring by Roy Rappaport (2000), or of early Christian history by Rodney Stark (1997). Of course, these are only some of the well-known studies focusing on particular spatio-temporal cases. We could have listed thousands of other important works by scholars who study religion. However, these three works have in common the willingness to admit that the particular cases studied are part of broader processes that, time and resources permitting, could be studied and included in the analyses of these phenomena. This is exactly the point that is being made here. The idea of generalizable knowledge involves a willingness to consider some parts of the studied case as more stable across individual occurrences, more essential, more influential compared to other parts. To cut the less stable, less essential and less influential parts might be hard for scholars in the humanities but nevertheless necessary if they do not wish to completely abandon the idea of generalizability. Note that the generalizability problem again evokes the reduction principle, although this time even within a single discipline. Generalization necessitates deciding what is core and transferrable to other cases while staying at the level and expertise of the initial discipline.

Given the assumption of decomposability and the possibility of selecting more stable and more variable features, we should be able to understand a particular spatio-temporal event within a religious system as part of the more general processes defining the workings of this system inside a specific ecological context. Since the workings of systems in similar ecological contexts should be guided by homologous processes, there is an opportunity to improve our understanding of micro-historical events by analyzing the general patterns. However, these general patterns need to be inferred and estimated from the micro-level, thick description, which is the pride of the humanities. That is, while previous generalizing accounts may have drawn a broad conclusion from anecdotal evidence or cherry-picked data that exactly fit the theory, the micro and macro levels of scholarship need to work in self-correcting cycles whereby general patterns are inferred from a thick, detailed description at the micro-level, and the micro-level patterns should be, in turn, predicted from general patterns. Any mismatches in such predictions should then feed back into the general model, correcting future predictions. The feedback-loop principle is a way to turn generalizing accounts into more responsible theories, which would be sensitive to local data and their variation. In other words, any generalizing theories of religious systems should work with a broad spectrum of micro-level data, rather than picking only specific examples. Such wellinformed generalizations may then have considerable predictive power when 
applied to different micro-level data in comparable socio-ecological contexts. However, such an approach demands a massive array of micro-level data organized in a systematic way that would allow for broader inferences.

Recently, the responsible estimation of general patterns from systematically organized micro-level data has become possible due to scholarly efforts to create various ethnographic and/or historical databases of religious systems, accumulating excellent scholarship on the micro-level (Guldi \& Armitage 2014; Slingerland \& Sullivan 2017; Watts, et al., 2015). While populating these databases with relevant micro-level data is a mammoth endeavor, the more data these databases will contain, the more qualified estimations of general patterns will be accessible, including the estimation of religious systems phylogenies (Gray \& Watts 2017; Slingerland \& Sullivan 2017). Moreover, tracking interactions between specific socio-ecological factors and the change of religious systems may hint at the systems' ability to adapt to ever-changing environments. For example, using the Ethnographic Atlas, Botero, et al., (2014) showed that increased belief in deities that have omniscient and punitive properties is associated with increased societal complexity and agricultural subsistence (change in the socio-ecological environment), and Watts, et al., (2015) used phylogenetic models to support this point using a database of Austronesian religions.

The database approach to estimating general patterns in the development and functioning of religious systems is just one example of how the scientific methods can be aligned with the emphasis on contextual variability in the humanities. Analogically, the micro and macro-level problems might be tracked in experimental research that aims to uncover universally shared human propensities. Such research, mostly based in the fields of psychology and neuroscience, often draws conclusions on the universal workings of the human mind from a single sample of university students in a given country (Sears 1986). Recently, this problem has been coined as the WEIRD people problem (Western Educated Industrial Rich Democratic), pointing out the narrow sampling of participants from very specific cultural backgrounds (Henrich, Heine, \& Norenzayan 2010b; 2010a). Data collected from these WEIRD participants have been used to make general claims about human propensities, ignoring potential cross-cultural variability. Again, as predicted by the complex adaptive systems approach and its emphasis on the cybernetic principle, it is to be expected that the functioning of the human mind in real-world situations will be influenced by multiple locally salient factors. Claims of universality need to be tested on populations from truly variable religious systems.

The WEIRD people problem has been lately of great interest to social scientists, including scholars studying religions (Henrich, et al., 2010; Lang, et al., 2016; Norenzayan 2016). For example, in a study of 15 small-scale societies that 
was focused on the effects of belief in omniscient and punitive gods on cooperation (supplementing the database studies mentioned above), Lang, et al., (2018) have found that belief in such deities predicts cooperative behavior toward anonymous co-religionists (see also Purzycki, et al., 2016; 2018). However, they did find substantial cross-cultural variation in this effect, supporting the assertion that contextual variability needs to be considered when inferring general trends in the workings of religious systems. Put differently, while Lang, et al., uncovered an important general pattern that statistically holds across 15 societies, a more detailed look into this effect in the specific societies uncovered further complexity that was not accounted for by this general pattern. Taking these local factors into account, as demanded by the complex adaptive systems approach, would be the next step in understanding the cross-cultural diversity of these findings.

\section{Temporal Depth}

In a seminal paper on cause and effect in biology, Ernst Mayr posed the following question: "Why did the warbler on my summer place in New Hampshire start his southward migration on the night of the 25th of August?" (1961:1502). Mayr offered four possible causes of the warbler's migration: 1) the warbler would not have sufficient food sources during winter; 2) migration is a genetically encoded trait of the warbler species; 3 ) the warbler detected a change in the length of daylight; 4) weather conditions were optimal for taking off that day. In this example, Mayr's point was that all four causes can be valid at the same time, they just address different layers of analysis: ultimate, dealing with evolutionary causes, and proximate, dealing with immediate intrinsic and extrinsic causes. Building on Mayr's work, Niko Tinbergen (1963) added the level of individual development (ontogeny), distinguishing among four analytical levels: 1) causation (how are traits activated); 2) survival value (how traits affect biological fitness);3) ontogeny (how traits develop during lifetime); and 4) evolution (how traits evolved phylogenetically). While the first and third levels concern the proximate causes, the second and fourth levels address ultimate effects and causes respectively. Applying these four levels in the case of the warbler's migration, it can be argued that migratory behavior evolved to secure the warblers' survival; and that the association between daylight length and migration, together with the warbler's sensitivity to light developed during ontogeny, are the immediate causes influencing the warbler's decision in a particular year.

Applying Tinbergen's insights on the topic of the current paper, the familiar tension between genetic and cultural determinism can be understood as encapsulated within the ultimate and proximate approaches. While scholars may 
study the adaptive functions of religious systems' components and their evolutionary history (e.g., rituals serve to alleviate anxiety and their basic structure are tractable to other non-human animals), the complete understanding of the workings of these components would be possible only while also accounting for the environmental influence during the components' developmental calibration (how are individuals socialized into religious systems and to ritual performance) together with specific environmental triggers (ecological conditions). Thus, the temporal depth might offer scholars important insights into the interactive relationship of genetic and socio-ecological factors while investigating religious phenomena. Currently, there are at least three distinct evolutionary approaches addressing the temporal depths that lie at the heart of interest of this article. They are evolutionary psychology, behavioral ecology, and gene-culture coevolution.

Evolutionary psychology primarily focuses on the mental adaptations that produce widespread behaviors of modern humans, studying the underlying psychological mechanisms and selective pressures that helped stabilize such behaviors (Barkow, Cosmides, \& Tooby 1992: 7). Thus, evolutionary psychology can best help with the proximate causes, explaining how traits function mechanistically while examining the question whether the trait was favored by natural selection or not. Scholars using this evolutionary framework usually identify specific selective pressures from the hypothesized Environment of Evolutionary Adaptations (EEA) where most of the genetic evolution took place and try to determine psychological mechanisms addressing the selective pressures (Tooby \& Cosmides 1990: $386-388$ ). The focus of evolutionary psychology on the selective pressures in the EEA makes it the most genetically conservative out of the three approaches-the discipline presupposes that most of the human cognitive mechanisms evolved in EEA (around 200000 years ago). As a consequence, evolutionary psychology concentrates mostly on panhuman universal traits, investigating their original adaptive functions (rather than current benefits) and to a large extent, disregards cross-cultural variability (e.g., universal sex differences in mate preferences: Buss 1989). Moreover, the focus on genetic evolution in the EEA has an important consequence for the analysis of current behaviors: since environments can rapidly change, certain general mechanisms might be maladaptive in the current environment, dubbed as "adaptive lag" (Daly \& Wilson 1999: 512-514). Indeed, humans currently live in artificial technology-dominated environments that are very different from the environments that humans spent most of their evolutionary history in.

Using the lenses of evolutionary psychology to study religious behavior, scholars examine genetically inherited psychological mechanisms that 
support religious systems, testing whether these mechanisms evolved specifically as parts of the system or for other types of beliefs and behaviors. Among the proponents of this approach, religious beliefs and behaviors are supported by specific combinations of low-level standard cognitive mechanisms evolved primarily for other purposes such as agency detection, coalitional psychology, contagion-avoidance, etc. (Boyer 2003: 122). For example, Schjoedt, et al., (2009) used functional magnetic resonance imaging (fMRI) to show that religious participants activate areas of "normal" (secular) social cognition, which are activated during communication with other people, when they pray.

Acknowledging the immense behavioral variability of our species, the second evolutionary approach, human behavioral ecology (HBE), focuses on the flexibility that makes this variability possible (E. A. Smith \& Winterhalder 1992a). In comparison to evolutionary psychologists, behavioral ecologists assume that humans are able to flexibly adjust their behaviors so that these behaviors adaptively respond to various socio-ecological conditions (E. A. Smith, Borgerhoff Mulder, \& Hill 2000: F22). This flexibility (or adaptability if you will) is, in turn, seen as humans' most important adaptation. The main objective of this evolutionary approach is to examine whether human behavioral variability in different geographical and historical ecologies results from fitness maximization. In contrast to evolutionary psychology, proponents of HBE do not examine underlying genetic, physiological or psychological mechanisms of studied adaptive behaviors, assuming that evolution is flexible enough to select and transmit optimal mechanisms (the so-called phenotypic gambit; E. A. Smith \& Winterhalder 1992b: 33). In this respect, human behavioral ecology and evolutionary psychology complement each other. While evolutionary psychology occupies itself mostly with the universal (adaptations) and the proximate (mechanisms), HBE aims to explain the variability (adaptiveness) and the ultimate (function/survival value). It tries to determine what ecological and social factors influence the behavioral variability both within and between populations and how this behavioral variability creates cultural differences.

The approach of behavioral ecology can be used in various ways to advance the study of religion (Sosis \& Bulbulia 2011). Scholars can ask questions such as: Do specific religious systems lead to adaptive outcomes within their respective ecologies? Are they adaptive compared to possible different configurations? Or which ecological factors determine the variation of religious systems both within and between populations? For example, the practice of some religious rituals may be an adaptive response to specific environmental pressures causing high rates of chronic illness. Research of the Sittirai Kavadi ritual (Xygalatas, et al., in press) showed that participants often report improving one's health as 
a motivation for participation in the ritual; and, moreover, that participation in Sittirai Kavadi is associated with improvements in self-assessed health.

Finally, the third of the evolutionary approaches is the framework of geneculture coevolution (GCC; Richerson \& Boyd 2005; Whiten, Ayala, Feldman, \& Laland 2017) that studies both genetic and cultural inheritance, including their interactions. GCC is best suited to ask and solve the most complex questions related to the temporal depth while studying religious phenomena because this approach combines not only proximate and ultimate levels but also specifically explores interactions between two evolutionary processes, that is, between genetic and cultural evolution. According to proponents of GCC, genetic evolution can, contrary to the common belief, be quite a rapid process, whereas cultural evolution can be, interestingly, very slow. ${ }^{10}$ Thus, these two processes run alongside each other and, importantly, can also act upon each other (exemplifying the cybernetic principle). Therefore, the GCC approach allows for the investigation of questions such as how much do genes shape cultures and, importantly, how much do cultures shape genes?

GCC shares the main assumptions of both previously discussed approaches because it postulates adaptive and universally shared psychological mechanisms for (among others) social learning but stresses that these mechanisms facilitate another crucial evolutionary process: socially obtaining new knowledge such as beliefs, ideas, values and norms that are adapted to particular environments (cultural evolution; Henrich 2016). By positing a feedback-loop between genetic and cultural evolution, GCC argues that the adaptive value of environmentally specific cultural knowledge created evolutionary pressures to select for brains that were highly specialized to readily obtain, store and use this knowledge. Crucially, once cultural knowledge became accumulated due to the adaptive psychological mechanisms for social learning, the knowledge could have been improved and extended, thereby creating a knowledge base that could be passed on to subsequent generations without the necessity for individuals to re-invent everything for themselves. This knowledge, in turn, provides adaptive value for specific environments, creating a second stream of adaptive inheritance - cultural transmission (Mesoudi 2016: 491). Ever since humans crossed this evolutionary Rubicon (Henrich 2016: 280), cumulative

10 Examples of the former often involve studies of human genome which show that approximately $10 \%$, mainly involving the genes responsible for our nervous system and the brain, are adaptations not older than $5^{0} 000$ years (Williamson, et al., 2007). Examples of the latter might include Acheulian and Oldowan industries which did not undergo major innovations for 900000 and 2.1 mil years respectively (Laland \& Brown 2011: 170). 
culture has started to significantly impact genetic evolution, reshaping human brains and guts. ${ }^{11}$

The interactions between genetic and cultural adaptations elegantly account for the tension between the genetic and cultural determinisms. ${ }^{12}$ Through cumulative culture, humans have constructed social niches, which were adapted to specific environments (Bulbulia 2012). These niches were scaffolded by the various interacting building blocks of religious systems, such as social norms, and institutions. Once the social niches were stable enough to hold over generations (most of them providing adaptive benefits), the niches created pressures on individuals to socialize into these constructions, substantially impacting members' behavior (cultural determinism). Importantly, in these new socio-ecological niches, genetic adaptations were often insufficient (new pressures), calling for further cultural adaptations (e.g., in religious systems, myth development to legitimize a new set of cooperative norms) or additional, yet much slower changes in the human genome itself (Derex \& Boyd 2015).

Given these theoretical developments, the GCC accounts of religion treat religious systems as a crucial component of human socio-ecological niche construction. As such, GCC scholars usually focus on adaptive socio-ecological niches in which genetic adaptations were not sufficient and postulate cultural mechanisms whereby the new selective pressures (created by the changed socio-ecological environments) might be answered. For example, Norenzayan, et al., (2016: 5) argue that the shift to agricultural forms of subsistence created new evolutionary pressures due to an increased societal size. The culturally evolved form of subsistence created new socio-ecological contexts (niches) where genetically driven mechanisms regulating cooperation (e.g., kin-selection or direct reciprocity) had limited efficiency. Harnessing evolved cognitive mechanisms such as the theory of mind, some religious systems reorganized so as to include punitive and monitoring moralizing gods who cared about human interpersonal conduct (cultural adaptation). In turn, belief in

11 A famous example of gene-culture coevolution is lactose tolerance, which is less common across the world than one might think. For populations that had historically domesticated cattle and used milk as a source of protein (a cultural practice), the adaptive value of such practice created selection pressures on genetic evolution, leading to gene recombination in order to allow for lactose digestion (Henrich 2016: 88-91).

12 A metaphor used by two pioneers of the GCC approach (in their vocabulary Dual Inheritance Theory), Peter Richerson and Robert Boyd, describing how the relationship looks like in their view, is also nicely illustrative, when they expand the original "genes have culture on the leash" (Lumsden \& Wilson 1985: 303) into: "Culture is on a leash, all right, but the dog on the end is big, smart, and independent. On any given walk, it is hard to tell who is leading who." (Richerson \& Boyd 2005: 194). 
such omniscient and punitive deities may have helped secure anonymous cooperative exchange, giving an adaptive edge to religious systems that involved moralizing gods.

Together, the three evolutionary approaches complement each other, showing that both rigid and flexible evolutionary processes may provide important insights into religious phenomena without the need to conform to either genetic or cultural determinism. These types of determinisms are oversimplifications of complex problems and mistaken solutions of the past. Nevertheless, such a conclusion will not fully appease the question of individual space for agency, that is, can we study religious phenomena without the need for either genetic or environmental influences on human behavior?

Combining insights from all three dimensions, we can surmise that human behavior is facilitated by myriads of evolved nested mechanisms that function in and are influenced by specific socio-ecological niches. Moreover, these niches have their own evolutionary history, which may be to some extent driven by random fluctuations. Applying these insights to the study of a single individual decision, general predispositions (genetic or environmental) will have only limited explanatory power. Nonlinear interactions between the myriads of factors comprising an individual decision will yield unpredictability (given that it is impossible to know all the initial conditions with infinite precision) and random fluctuations will also play an important role. Individual agents may even behave as if denying evolutionary and mechanistic principles (e.g., suicide, decision not to reproduce). However, the more we scale the unit of analysis toward larger spatio-temporal events, the more regularities in the behaviors of religious systems we find because the basic structure of these systems (e.g., as defined by Sosis) constrains their possible behavioral variation. Zooming out from individual cases, the evolutionary and mechanistic levels of analysis will be more and more powerful in illuminating the hidden causes of the behavior of religious systems.

An Example of 3D Integration

On Wednesday, May 14, 2014, at 4:30 AM, the Tamil Sittirai Kavadi festival began in the Kovil Montagne temple in Quatre Bornes, Mauritius. Following nine days of prayers, fasting, sex taboos, and other austerities, the festival started with morning prayers in the Kovil while at the same time, Kavadi participants started to slowly gather in another temple located approximately $1.5 \mathrm{~km}$ from the Kovil. At the gathering point, the participants brought their small altars called kavadis, lining them up in rows in the temple garden and putting the 
finishing touches to them. Kavadis are portable altars fixed to bamboo or aluminum structures that often have a small statue or picture of the Tamil god Muruga inside. Ritual participants carry these altars on their shoulders during a procession to the Kovil Montagne as a symbolic burden to please Muruga, to whom many participants took vows related to curing illnesses or repenting for misbehavior.

As time progressed, more and more people gathered at the temple garden with their kavadis, reaching a climax of about 3000 participants cramped in a relatively small garden with almost no space to walk. Before embarking on the procession to the Kovil temple, many participants had their cheeks, tongues, and bodies pierced with either single or multiple needles, skewers, or hooks, commemorating Muruga's lance $(v e l)$. During the piercing sessions, participants were usually surrounded by a group of drummers who tried to impose trance states on participants by loud drumming, shouting alternatively into the right and left ears of the participants, and burning incense sticks.

Around 10AM, under a cloudy sky and occasional showers, the Kavadi participants together with their families and supporters departed in a procession to the Kovil Montagne, with priests, temple elders, and a statue of a peacock symbolizing Muruga at the front, followed by participants carrying variously sized kavadis on their shoulders (usually men) or pots with milk (paal kudam) on their heads (usually women). The participants wore magenta-colored cloths (traditional color of Mauritian Tamils), walked barefoot, or on nail slippers. During the procession, the participants were accompanied by musical performers, they prayed or danced ecstatically, getting into a trance. At the end of the procession, several participants engaged in extreme practices such as carrying metal structures encapsulating whole bodies, piercing the body in hundreds of places, or dragging chariots in the form of Muruga's temples with hooks attached to their skin. Upon reaching the Kovil's lower ground, the participants had to climb 230 steps up to the mountain temple where they laid down their kavadis in front of Muruga's statue and the priests removed the piercings from the participants' bodies. The full procession took around six hours by the time the last participants arrived at the Kovil Montagne. We estimated that around 10,000 people took part in the procession. The Sittirai Kavadi festival was concluded with prayers and a festive dinner called the "seven curries".

This short ethnographic description of a particular spatio-temporal event illustrates a specific process in the functioning of a Tamil religious system located in Quatres Borne. As scholars of religion, we may wish to explicate factors that led to the occurrence of this event, its current form, its position within the religious system, and, crucially, its role in influencing the system's 
cooperative and reproductive outputs. ${ }^{13}$ Positing this event within the $3 \mathrm{D}$ integrative space as displayed in Fig. 1, we can imagine three basic axes: on the contextual width axis we can move from right to left, from the most specific to the most universal context; on the mechanistic height axis we can move top down from most complex phenomena to most simple mechanisms; and on the temporal depth axis we can move from the shallowest current events to the deepest evolutionary levels. Thus, our ethnographic example of the specific kavadi ritual would start from where the contextual width is the broadest, the mechanistic height the highest and the temporal depth the shallowest. To explicate the factors leading to the occurrence of this event in its current form, we could, for instance, go deeper on the temporal depth dimension and track the history of Sittirai Kavadi performed in the Kovil Montagne back to its first performance in 1941. Alternatively, we could track how kavadi structures evolved from predominantly bamboo based to predominantly aluminum based or we could elucidate how this specific ritual was organized by temple elders, explicating their individual influences. Going even deeper on the temporal axis, we could track the formal coalescence of this particular religious system in Quatres Borne back to 1897 or study the history of Tamil diaspora in Mauritius. All these historical events would have had impact on the specific spatio-temporal event. Moreover, these historical aspects might help us understand the specific history and evolution of a particular socio-ecological niche in which our participants interact (more on that below).

Further insights into the Sittirai Kavadi could be gained by moving left on the contextual width scale toward more generalizability. We could study kavadi practices performed by similar religious systems (other Tamil communities in Mauritius) or by geographically and historically more distant religious systems (Tamil communities in India, Sri Lanka, or Malaysia), which could help us identify the more cross-culturally stable factors, and factors that are specific for the Sittirai Kavadi under investigation. At this level of contextual width, we may also look at general contours of the mythical narration related to carrying kavadi (detailed, e.g., in Willford 2002) that may play an important role in legitimizing this event, including textual analysis of narrations about Kavadi. Or we could look at cross-cultural demographic profiles of kavadi participants. Simultaneously, we could go deeper on the temporal axis, tracking the concept of kavadi to its historical roots in Tamil Nadu.

Generalizing the kavadi practice several steps further as a type of extreme religious ritual, we could compare kavadi practices with penile subincision

13 We would, in fact, use much more detailed ethnography of such an event. We kept the description short for the sake of the argument. 
performed by the Australian tribe Arunndta on their young male initiates (Basedow 1927; Pounder 1983), with self-flagellation and crucifixion performed by Roman Catholics in San Pedro Cutud on Black Friday (Pineda \& BonifacioRamolete 2008), with the Yoruba practice of scarification (Ojo 2008), or with the Shia Muslim masirat in South Lebanon where participants hurt themselves with machetes and whips during Ashura (Deeb 2005). Moving deeper on the temporal axis, we can ask questions pertaining not only to the history of religious painful practices (e.g., Maya penile blood-letting; Munson, Amati, Collard, \& Macri 2014) but widen the net to include cultural history of nonreligious counterparts of painful practices and also investigate the deeper evolutionary histories of such practices in related species (living or extinct). That is, we can examine the possible ultimate functions that painful rituals serve within religious systems (why have painful rituals evolved), which would give us substantial explanatory power when studying the specific Sittirai Kavadi. Note that for the investigation of ultimate functions, the specific content of painful practices will become less important and more emphasis will be placed on their structural features (Rappaport 1999:3).

A hypothesized ultimate function of painful rituals within a religious system is their ability to communicate the performer's commitment to a specific group and/or deity (Bulbulia \& Sosis 2011: 364-370; Sosis 2003: 92-94). Drawing from theories in HBE (Irons 2001; Zahavi 1975), evolutionary scholars hypothesized that honestly communicating commitment to a group (specific religious system) can be adaptive for both the sender and receivers of such communication because commitment signaling is directly transferable into cooperative dilemmas. In situations where potential cooperative partners cannot trust each other's motivations and a possibility of free-riding exists, language will be a poor commitment signal of adherence to cooperative norms because it can be easily faked. However, undergoing painful (and otherwise costly) rituals that are seen as moral obligations within a given religious system sends a strong signal of commitment to the particular religious system. Since ritual participants are willing to harm themselves in order to fulfill the religious system's moral obligations, it is highly likely that they will also abide by other norms posed by the system.

For instance, undergoing ritual crucifixion on Black Friday in the Philippines will be most likely associated with keeping to the moral obligations required by the Roman Catholic Church's catechism throughout the year. The ritual practitioner undergoing crucifixion might be seen as a reliable cooperative partner for other members of the religious system. Indeed, there is growing evidence from various religious systems supporting this conclusion (Power 2016; Shaver, Lang, et al., 2018; Sosis \& Ruffle 2003; Xygalatas, et al., 2013). Given 
the self-regulatory feedback loops typical for complex adaptive systems, painful rituals affording to signal a commitment to a group's moral obligations might be adaptive in facilitating higher cooperative outputs in times of crises (Sosis, Kress, \& Boster 2007), therefore proliferating the system itself. Applying this insight to our example, we can partially explain the occurrence of Sittirai Kavadi as motivated by the need for reinforcement of norms and bonds within the Tamil community in Quatres Borne, which later translates into cooperative output. Importantly, with the integrative approach, such claims can be tested, and there is some evidence that a different kavadi ritual performed at the Kovil Montagne indeed has the positive cooperative effects (Xygalatas, et al., 2013).

At this level of generality on the contextual width axis, it would be useful to start with the mechanistic analysis of painful rituals, that is, their proximate functions. Given the hypothesized ultimate function of such rituals (increased cooperative outputs), we could look at how this effect is buttressed by individual participants and their psycho-physiological systems. While we expect huge inter-individual variation in the ways that people engage in painful rituals, at this level of generality, we can study a prototypical individual as the most average cross-cultural denominator. Starting the analysis of mechanisms at conscious, self-declared motivations for participation, the most shared motivation can be something like 'showing my devotion to god(s)'. Note that such selfdeclared motivation does not need to be in agreement with the hypothesized ultimate function. ${ }^{14}$ In fact, it is not only gods who (allegedly) receive the signal of commitment, but importantly, also the community and ritual practitioners themselves(in other words, ritual participants are adjusting their reputation about commitment to religious norms). Note that at this level of mechanistic decomposition and contextual generality, we could decide to go into greater depth on the temporal axis and explore the evolution of the mechanism for reputational concerns. The ability to assess others' reputation emerged as a crucial principle regulating human cooperation known as indirect reciprocity (Trivers 1971). That is, with growing population size, humans cannot rely on previous cooperative exchange with all individuals (direct reciprocity) and must rely on others' cooperative reputation, which is regulated by observation and gossip (Dunbar 1998; Dunbar \& Sosis 2018). Thus, signaling a commitment to a particular religious system has a firm bedrock in underlying evolved reputational mechanisms.

14 The conscious motivation for participation in painful rituals may modify the whole workings of the system (see below) but for the sake of argument, let us assume that the ritual participants' main aim is congruent with the hypothesized function, that is, to display their devotion. 
Focusing on the specific elements of commitment communication such as perceived pain, energy expenditure, or displayed trance states, we could investigate how these individual mechanisms facilitate the signaled cooperative behavior. Here, we would hypothesize that all three signal types will support the cooperative function of painful rituals and, moreover, that these factors will be mutually interacting, and exponentially amplifying each other (e.g., more piercings and energy expenditure will more likely lead to trance states and, together, produce the highest effects on cooperative behavior). Focusing specifically on perceived pain, there is indeed evidence supporting its role in fostering social bonds (Bastian, Jetten, \& Ferris 2014; Whitehouse, et al., 2017). Perceived pain can be further decomposed into various neural and neuroendocrine mechanisms such as the cortex, limbic system, thalamus, which trigger an analgesic response to pain via the brain opioid system (Machin \& Dunbar 2011). Interestingly, while beta-endorphins are released as a natural analgesic in reaction to pain, they were also shown to facilitate social bonding and cooperation in general (Lang, Bahna, Shaver, Reddish, \& Xygalatas 2017; Tarr, Launay, \& Dunbar 2014). Furthermore, at this level of mechanistic decomposition, we could again investigate the evolutionary dimension of the endogenous opioid system, looking at its possible adaptive functions (which are harnessed, among others, by religious systems in the form of painful rituals). Together, this analysis illustrates how one ultimate function (increased cooperative output) can be step-by-step tracked down on the mechanistic axis from the more general level (conscious motivation for participation) to the lower level (neuroendocrine system) while buttressed or corrected by evolutionary history of particular mechanisms (reputational concern, neuroendocrine system).

In theory, we could continue going even lower with mechanistic decomposition, for example, investigating the amino acid sequence of beta-endorphins. However, it may be more interesting to slide to the right on the axis of contextual width to more specific rituals and see which factors we might need to incorporate into the mechanistic analysis to get closer to particular observed phenomena. For example, there is an ongoing debate whether painful rituals must be legitimized by belief in supernatural agency in order to have the desired effect on group cooperation (Shaver, DiVietro, Lang, \& Sosis 2018; Sosis \& Bressler 2003). Thus, the presence and type of supernatural agency in a specific religious system may critically modify the resulting effects of painful rituals on group cooperation. Moving up on the mechanistic height dimension and right on the contextual width to more detailed context again, we can also account for specific selective pressures within the socio-ecological niche of the Quatres Borne religious system (explicated by our historical analysis). For example, members of the Quatres Borne community may suffer (due to various 
historical reasons) from high rates of chronic illnesses. Thus, an increase in the performance Sittirai Kavadi may be an adaptive response to such specific pressures (Lang 2018; Xygalatas, et al., in press).

At this point, it is probably becoming obvious how gargantuan this approach may become. Indeed, we have selected only a few areas on the ${ }_{3} \mathrm{D}$ integrative space (Fig. 1) to illustrate our point. By no means could the examples given aspire at a composite model of a particular religious system. Instead, we aimed to emphasize the possibility of moving in any direction within the $3 \mathrm{D}$ integrative space whereby each of these directions would provide important insights into the studied phenomenon. Importantly, our approach relies on the mutual corroboration of theories across the various studied dimensions.

\section{Discussion and Future Challenges}

The aim of this paper was to argue for interdisciplinary cooperation in the study of complex cultural phenomena with a particular focus on religion and to offer ways for systematizing knowledge across the various disciplines that study religions. Generally, treating cultural phenomena as complex adaptive systems allows scholars to build models that would integrate theories and piecemeal evidence anchored in various coordinates of the $3 \mathrm{D}$ integrative space (Fig. 1). The complex adaptive system approach demands such piecemeal evidence to be interpreted only within the specific section of the $3 \mathrm{D}$ space (e.g., experimental study of cognitive mechanisms in a particular population, or a religious system in a particular spatio-temporal context) without any unwarranted generalizing claims about the workings of the whole system. However, with proper representation of contextual diversity and sufficiently low or deep level of mechanistic/temporal analysis, generalizing claims are warranted and have important value in explicating large behavioral and evolutionary patterns (e.g., the study of the evolution of ritual behavior as a communication technology). Employing such interpretative humility together with the willingness to see the results of specific research as part of broader processes in the ${ }_{3} \mathrm{D}$ integrative space should afford the mutual corroboration of theories anchored in the separate dimensions while also sparking new theories emerging from the combination of these dimensions.

However, while stressing the benefits of knowledge integration, we do not mean to argue for causal completeness or total unity of sciences. Rather, we aim to illustrate how scientists and humanists may find common ground in studying religion by employing the $3 \mathrm{D}$ integrative model of complex adaptive systems and why this approach may be useful in pushing the understanding of 
religious phenomena forward. We think about our approach more as a useful tool for building interdisciplinary knowledge, a tool that needs much honing and reworking, but which can offer insights into the tension points between the sciences and the humanities. Below, we offer some clarification and some of the bigger remaining issues that need to be worked out in the future.

First, our aim was not to argue that religious phenomena can be studied as deterministic to the last painstaking detail. Our approach leaves an important space for individual agency, which will be more and more important while zooming in on a specific case. Importantly, however, the complex adaptive systems approach explains how individual agency arises from deterministic patterns, thereby allowing scholars to integrate such agency into broader patterns and, to some extent, helping to bridge the humanities-sciences divide. While we believe that general patterns have important explanatory power, specific spatio-temporal cases might be best studied as having their own agency (whether or not that is actually true). We acknowledge that our own studies are heavily biased toward general patterns and the study of evolved cognitive mechanisms. However, we also acknowledge the critical need for more individual-based approaches that can help understand specific cases, assuming these approaches are willing to be connectable to broader patterns.

Second, we readily embrace the basic scientific principles such as model building and hypotheses testing, which create the basis of our integrative proposal. We realize that this approach to the integration of the humanities and the sciences in the study of religion is skewed toward the sciences and might not be appealing to all humanistic scholars. For many proponents of human incomparable exceptionality, the humanities will always remain a distinct academic endeavor not connectable with other scientific disciplines. With our proposal, we aimed more toward scholars sympathetic to the interdisciplinary study of religions who nonetheless may be discouraged by the generalizing and often overly reductive claims made in the life sciences. Hopefully, this paper offered creative tools for thinking about human complexity and suggested useful ways to give proper credit to individual cases while, at the same time, not rejecting inference from broader patterns. Similarly, by embracing the cybernetic principle of religious system, we simultaneously put forward that religious phenomena, ultimately, impact biological fitness and that, therefore, these phenomena evolve to serve adaptive functions. We realize that some scholars might be reluctant toward biological functionalism as introduced by Bronislaw Malinowski. Nevertheless, we believe that the assumption of adaptive roles of religious phenomena is well supported by the neo-Darwinian synthesis and that the problems inherent in Malinowski's functionalism have been sufficiently addressed (e.g., see Sosis \& Handwerker 2011: 41). For scholars 
willing to admit that religious phenomena may be influenced by and, in turn, can influence biological fitness, the cybernetic principle offers a powerful tool to remedy the nature vs. nurture tension.

Third, some scholars of religion may also read our proposal as if we would call for all students of religion to master psychology, biology, neuroscience, or physics. However, that would be far from what we are suggesting. As Slingerland and Collard (2011: 24-26) nicely explained, the integrative approach presupposes that most scholars will continue working in their own fields, producing field-specific knowledge. Our proposal is merely a call for a common perspective that would allow scholars from various disciplines to employ their expertise and skills when jointly investigating a shared topic. Of course, by working in their own fields, scholars will build models that will include the whole range of, for example, mechanistic composition, but will be anchored only in a narrow segment of cultural specificity. However, scholars educated in contextual disciplines can enrich the suggested mechanisms with external proximate causes, thereby widening the contextual width axis and stimulating the redefinition of a mechanism's components and organization; or emphasize why such a mechanistic model does not apply to a well-understood individual case and suggest ways to improve the model.

We believe that enriching general models with specificities of local religious systems is the most fruitful area for cooperation between the humanities and the sciences; that is, plugging in specific factors related to particular events into more general models and looking at how these factors affect the workings of that model. Such factors can address which cultural systems embed the actor's behavior, what is the role of institutions in these systems, what are the behavioral norms, or how people rationalize their decisions. In other words, this layer can analyze contextualized motivations, intentions, and values. Methods used on this level of contextual width can range from ethnographic observation and comparison, through historical textual analysis, survey research, to psychological experiments. ${ }^{15}$ Furthermore, since institutional practices and discourses can be regarded as an indispensable part of one's socio-ecological niche, social construction theory (Berger \& Luckmann 1991) and discourse analysis (Taira 2013; von Stuckrad 2013) can investigate how people navigate through these cultural niches and use or misuse their power relations to maximize their inclusive biological fitness.

15 Admittedly, scholars working only with text might not have enough data to include other levels than the external proximate causes although they can leave the possibility of otherlevel explanations open for researchers willing to bring additional evidence from different disciplines. For a good example, see Chalupa (2014). 
Finally, some scholars may read our proposal as if applicable to the whole academia. Indeed, the original Wilson's (1998) proposal of consilience had such aims. Throughout the paper, we suggested that this approach should be applicable also to other complex cultural systems other than religions. However, this may not be feasible in other humanistic fields such as, for example, film studies or library science. While these fields will be enriched with the knowledge of evolved psychological mechanisms, the subjects of their study usually do not constitute complex adaptive systems. Our approach will be more suitable to the more basic and cross-culturally widespread means of societal organizations that significantly affect human cooperative niches.

Having laid out some clarification of our main points, we now turn to important outstanding issues, which impede the integrative approach to really reach its full potential. First, we presented a simplistic integrative model that assumed intra-disciplinary agreement on particular phenomena, but as colleagues from any academic field may attest, such agreements are hard to come by. Our aim was to put any longstanding feuds and disagreements aside for a moment in order to build a vision of integrated knowledge. Thus, our integratory principle works on a general level, but scholars of religion will face dilemmas regarding which theory to select in the reconstruction of religious phenomena while working with lower/higher-level disciplines. Often, scholars will have to side with particular theories that may be closer to their mindset because there might yet not be sufficient evidence to decide between the competing theories. The same problem would apply when looking for heuristic identities across disciplines. However, we believe that the mutual corroboration of theories on different levels of academic investigation may partially help with these issues - theories, viewed as competing at a particular level, might be resolved by knowledge from lower/higher-level disciplines.

Second, selecting stable factors across religious systems for evolutionary and mechanistic analyses may encounter considerable difficulties when agreeing whether two systems really contain the same factor (is Buddha a moralizing god comparable to Allah?). This is where detailed knowledge of micro-context would play a crucial role, assuming that experts are willing to look for comparative consensus and place the phenomenon within broader patterns. Similar problems may arise when selecting the analytical boundaries of religious systems. Is the Tamil community in Quatres Borne a separate and distinguishable religious system from the Marathi community in La Gaulette in Mauritius? Or are those communities best understood as part of a more general system of Mauritian Hinduism? Thus, there is still a large space for improvement based on the long history of discussion within the comparative study of religions.

Furthermore, working with general patterns while accounting for contextual variability on the micro-level presents substantial intellectual challenges. 
Creating models of religious phenomena that would usefully resemble the world in order to reach important insights and avoid unfounded generalizations will require detailed knowledge of the mechanisms' functioning and their relationships. Importantly, it also requires massive computational power, especially if we start modeling systems to a detailed factorial level (e.g., tens of factors). While such models might be closer to the reality and contextual specificity, their complex nature (multiple parts interacting in a nonlinear fashion) will often lead to unpredictable results that are typical for deterministic chaos and that crucially depend on the setup of initial conditions. Put differently, taking into account all the factors within one theory and testing whether this theory sufficiently captures observed phenomena is cognitively extremely demanding and impossible for a single human being.

To some extent, this problem can be circumvented by employing computational approaches to the study of complex systems, which are gradually establishing their position within religious studies (Kaše, Hampejs, \& Pospíšil 2018; Lane \& Shults 2018; Nielbo, Braxton, \& Upal 2012). Computer modeling and simulations afford researchers to specify factors of interest and their relationships (be it neuronal components of a cognitive mechanism or a group of agents with different properties) and assess how these factors may give rise to the phenomena studied. With computer simulations, scholars can evaluate the quality of their reverse-engineering attempts (mechanistic decomposition) and compare the reconstructed systems with phenomena observed in real life. Of course, the selection of factors and their assumed weight (based on the ethnographic description and experimental testing) will create another type of tensions between scholars, prompting questions such as "Is this factor really so important for this particular phenomenon?" or "Do we need all these unimportant factors when my factor explained $90 \%$ of variability in the phenomenon"? Indeed, this is an important task for future research, in which both scientists and humanists must play a crucial role, to specify the model parameters in such a way as to provide insights into the workings of particular religious systems.

In conclusion, we believe that the study of religion is on the verge of a new and exciting phase, marked by interdisciplinary cooperation that would afford complex understandings of religious phenomena. These understandings may have a major influence on our quickly changing world, in which religions play, for better or worse, immensely important roles. Synthetizing contextual, mechanistic, and evolutionary explanations to understand the ways that religious systems influence micro and macro events in our world may eventually lead to better predictive abilities that may help find solutions for the malignant issues that our world faces today. Arguably, this step is even more challenging than bridging the humanities-science divide. 


\section{Acknowledgments}

Short parts of this manuscript were rewritten from M.L.'s doctoral thesis at Masaryk University. We would like to thank Lloyd Black, Radim Chvaja, Richard Sosis, Dimitris Xygalatas, and anonymous reviewers for their comments during the various stages of the development of this manuscript. This work was funded by the generous support of the Czech Science Foundation (GA CR) [18-18316S].

\section{References}

Albright, C. R. (2000). "The "God Module" and the complexifying brain. Zygon 35(4), pp. $735-744$.

Ambasciano, L. (2016). "Mind the (unbridgeable) gaps." Method \& Theory in the Study of Religion 28(2), pp. 141-225. https://doi.org/10.1163/15700682-12341372.

Asprem, E. \& Taves, A. (2018). "Explanation and the study of religion." In: B. Stoddard, ed., Method Today: Redescribing Approaches to the Study of Religion. Sheffield: Equinox Publishing, pp. 133-157.

Barkow, J. H., Cosmides, L., \& Tooby, J. (1992). The Adapted Mind: Evolutionary Psychology and the Generation of Culture. New York, Oxford: Oxford University Press.

Basedow, H. (1927). "Subincision and kindred rites of the Australian Aboriginal." Journal of the Royal Anthropological Institute of Great Britain and Ireland 57, pp. 123-156.

Bastian, B., Jetten, J., \& Ferris, L. J. (2014). "Pain as social glue: Shared pain increases cooperation.” Psychological Science 25(11), pp. 2079-2085. https://doi.org/10.1177/ 0956797614545886.

Bechtel, W. (2008). Mental Mechanisms: Philosophical Perspectives on Cognitive Neuroscience. New York, London: Routledge; Tylor and Francis Group.

Bechtel, W. (2011). "Mechanism and biological explanation." Philosophy of Science 78(4), pp. 533-557.

Bechtel, W., \& Abrahamsen, A. (2010). "Dynamic mechanistic explanation: Computational modeling of circadian rhythms as an exemplar for cognitive science." Studies in History and Philosophy of Science Part A 41(3), pp. 321-333. https://doi .org/10.1016/j.shpsa.2010.07.003.

Bechtel, W., \& Richardson, R. C. (2010). Discovering Complexity: Decomposition and Localization as Strategies in Sceintific Research (Vol. 1). Cambridge, MA; London: The MIT Press. https://doi.org/10.1017/CBO9781107415324.004.

Berger, P. L., \& Luckmann, T. (1991). The Social Construction of Reality: A Treatise in the Sociology of Knowledge. London: Penguin Books. https://doi.org/10.2307/323448. 
Botero, C. A., Gardner, B., Kirby, K. R., Bulbulia, J., Gavin, M. C., \& Gray, R. D. (2014). “The ecology of religious beliefs." PNAS 111(47), pp. 16784-16789. https://doi.org/10.1073/ pnas.1408701111.

Boyer, P. (2003). "Religious thought and behaviour as by-products of brain function." Trends in Cognitive Sciences 7(3), pp. 119-124. https://doi.org/10.1016/S1364 -6613(03)00031-7.

Boyer, P., \& Liénard, P. (2006). "Why ritualized behavior? Precaution systems and action parsing in developmental, pathological and cultural rituals." Behavioral and Brain Sciences 29, pp. 1-56. https://doi.org/https://doi.org/10.1017/So140525Xo6oo9332.

Bulbulia, J. (2012). “Spreading order: religion, cooperative niche construction, and risky coordination problems." Biology \& Philosophy 27(1), pp. 1-27. https://doi.org/10.1007/ s10539-011-9295-x.

Bulbulia, J., \& Slingerland, E. (2012). "Religious studies as a life science." Numen 59, pp. 564-613.

Bulbulia, J., \& Sosis, R. (2011). "Signalling theory and the evolution of religious cooperation." Religion 41(3), pp. 363-388.

Buss, D. M. (1989). "Sex differences in human mate preferences: Evolutionary hypotheses tested in 37 cultures." Behavioral \& Brain Sciences 12(1), pp. 1-49.

Carroll, J., Johnson, J. A., Salmon, C., Kjeldgaard, J., Clasen, M., \& Jonsson, E. (2017). "Beliefs about human nature, culture, and science: Survey and symposium." Evolutionary Studies in Imaginative Culture 1(1), pp. 1-32.

Chalupa, A. (2014). "Pythiai and inspired divination in the Delphic oracle: Can cognitive sciences provide us with an access to "dead minds"?" Journal of Cognitive Historiography 1, pp. 24-51. https://doi.org/10.1558/jch.vii1.24.

Cho, F., \& Squier, R. K. (2008). "He blinded me with science': Science Chauvinism in the study of religion." Journal of the American Academy of Religion 76(2), pp. 420448. https://doi.org/10.1093/jaarel/lfnoo1.

Daly, M., \& Wilson, M. (1999). "Human evolutionary psychology and animal behaviour." Animal Behaviour 57, pp. 509-519. https://doi.org/10.1006/anbe.1998.1027.

Deeb, L. (2005). "Living Ashura in Lebanon: Mourning transformed to sacrifice." Comparative Studies of South Asia, Africa and the Middle East 25(1), pp.122-137. https://doi.org/10.1215/1089201X-25-1-122.

Derex, M., \& Boyd, R. (2015). "The foundations of the human cultural niche." Nature Communications 6, p. 83-98. https://doi.org/10.1038/ncomms9398.

Dilthey, W. (1883/1988). Introduction to the Human Sciences: An Attempt to Lay a Foundation for the Study of Society and History. Wayne State University Press.

Dunbar, R. I. M. (1998). Grooming, Gossip, and the Evolution of Language. Cambridge, MA: Harvard University Press. 
Dunbar, R. I. M., \& Sosis, R. (2018). “Optimising human community sizes.” Evolution and Human Behavior 39(1), pp. 106-111. https://doi.org/10.1016/j.evolhumbehav.2017.11.001. Dupré, J. (1996). "Metaphysical disorder and scientific disunity." In: P. Galison \& D. Stump, eds., The Disunity of Science: Boundaries, Context, and Power. Standforf, California: Standford University Press, pp. 101-17.

Durkheim, E. (1912/1964). The Elementary Forms of the Religious Life. London: George Allen \& Unwin LTD.

Eilam, D. (2006). "Ritualized behavior in animals and humans: Time, space, and attention." The Behavioral and Brain Sciences 29(6), pp. 22-23.

Evans-Pritchard, E. (1956). Nuer Reiligon. Oxford: The Clarendon Press.

Freud, S. (1961). The Future of an Illusion. New York: WW Norton \& Company Inc. https://doi.org/10.1017/CBO9781107415324.004.

Geertz, A. (2008). "How not to do the Cognitive Science of Religion today." Method \& Theory in the Study of Religion 20(1), pp. 7-21. https://doi.org/10.1163/1570068o8X 260232.

Geertz, C. (1983). Local Knowledge: Further Essays in Interpretative Anthropology. London: Fontana Press.

Geertz, C. (1973). The Interpretation of Cultures: Selected Essays. New York: Basic Books.

Gray, R. D., \& Watts, J. (2017). "Cultural macroevolution matters." Proceedings of the National Academy of Sciences 114(30), pp. 7846-7852. https://doi.org/10.1073/ pnas.1620746114.

Guldi, J., \& Armitage, D. (2014). The History Manifesto. Cambridge: Cambridge University Press.

Hamer, D. (2005). The God Gene: How Faith is Hardwired into our Genes. New York: Anchor Books.

Henrich, J. (2016). The Secret of Our Success: How Culture Is Driving Human Evolution, Domesticating Our Species, and Making Us Smarter. Princeton, Oxford: Princeton University Press.

Henrich, J., Ensminger, J., McElreath, R., Barr, A., Barrett, C., Bolyanatz, A., ... Ziker, J. (2010). "Market, religion, community size and the evolution of fairness and punishment." Science 327, pp. 1480-1484.

Henrich, J., Heine, S. J., \& Norenzayan, A. (2010a). "Most people are not WEIRD." Nature 466, p. 29. https://doi.org/10.1017/So140525Xo999152X.

Henrich, J., Heine, S. J., \& Norenzayan, A. (2010b). "The weirdest people in the world?" The Behavioral and Brain Sciences 33(2-3), pp. 61-83; discussion 83-135. https://doi .org/10.1017/So140525Xo999152X.

Holland, J. H. (1992). “Complex adaptive systems.” Daedalus 121(1), pp. 17-30.

Inzlicht, M., McGregor, I., Hirsh, J. B., \& Nash, K. (2009). "Neural markers of religious conviction." Psychological Science 2o(3), pp.385-92. https://doi.org/10.1111/ j.1467-9280.2009.02305.x. 
Irons, W. (2001). "Religion as a hard-to-fake sign of commitment." In: R. Nesse, ed., Evolution and the capacity for commitment. New York: Russell Sage, pp. 292-309.

Kaše, V., Hampejs, T., \& Pospíšil, Z. (2018). "Modeling cultural transmission of rituals in silico: The advantages and pitfalls of agent-based vs. system dynamics models modeling." Journal of Cognition \& Culture 18, pp. 483-507. https://doi.org/10.1163/ 15685373-12340041.

Kundt, R. (2015). Contemporary Evolutionary Theories of Culture and the Study of Religion. London, New Delhi: Bloomsbury Academic.

Laland, K. N., \& Brown, G. R. (2011). Sense and Nonsense: Evolutionary Perspectives on Human Behaviour. Oxford: Oxford University Press. https://doi.org/10.1080/15265161 .2011.623817.

Lane, J. E., \& Shults, F. L. (2018). “Cognition, culture, and social simulation." Journal of Cognition and Culture 18, pp. 451-461. https://doi.org/10.1163/15685373-12340039.

Lang, M. (2018). "Multifunctional religious systems and perturbed dynamics of psychological wellbeing." Religion, Brain \& Behavior. E-pub before print. https://doi.org/10 $.1080 / 2153599 X .2018 .1532454$.

Lang, M., Bahna, V., Shaver, J. H., Reddish, P., \& Xygalatas, D. (2017). "Sync to link: Endorphin-mediated synchrony effects on cooperation." Biological Psychology 127, pp. 191-197. https://doi.org/https://doi.org/10.1016/j.biopsycho.2017.06.oo1.

Lang, M., Krátký, J., Shaver, J. H., Jerotijević, D., \& Xygalatas, D. (2015). “Effects of anxiety on spontaneous ritualized behavior." Current Biology 25(14), pp. 1892-1897. https:// doi.org/10.1016/j.cub.2015.05.049.

Lang, M., Mitkidis, P., Kundt, R., Nichols, A., Krajčíková, L., \& Xygalatas, D. (2016). "Music as a sacred cue? Effects of religious music on moral behavior." Frontiers in Psychology 7(814), pp. 1-13. https://doi.org/10.3389/fpsyg.2016.00814.

Lang, M., Purzycki, B. G., Apicella, C. L., Atkinson, Q. D., Bolyanatz, A., Cohen, E., Handley, C., Kundtová Klocová, E., Lesorogol, C., Mathew, S., McNamara, R. A., Moya, C., Placek, C. D., Soler, M., Vardy, T., Weigel, J. L., Willard, A. K., Xygalatas, D., Norenzayan, A. \& Henrich, J. (2019). "Moralizing gods, impartiality, and religious parochialism across 15 societies." Proceedings of the Royal Society B: Biological Sciences 286 (1898), pp. 1-10. https://doi.org/10.1098/rspb.2019.0202.

Liénard, P., \& Boyer, P. (2006). "Whence collective rituals? A cultural selection model of ritualized behavior." American Anthropologist 108(4), pp. 814-827. https://doi .org/10.1525/aa.2006.108.4.814.

Lumsden, C. J., \& Wilson, E. O. (1985). "The relation between biological and cultural evolution." Journal of Social and Biological Systems 8(4), pp. 343-359. https://doi .org/10.1016/0140-1750(85)90042-9.

Machin, A. J., \& Dunbar, R.I. M. (2011). "The brain opioid theory of social attachment: A review of the evidence." Behaviour 148(9), pp. 985-1025. https://doi .org/10.1163/000579511X596624. 
Malinowski, B. (1948). Magic, Science and Religion and Other Essays (1992nd ed.). Long Grove, Il: Waveland Press Inc. https://doi.org/10.2307/2104095.

Martin, L. H., \& Wiebe, D. (2017). Religion Explained? The Cognitive Science of Religion after Twenty-five Years. London, New York: Bloomsbury Academic.

Mayr, E. (1961). "Cause and effect in biology." Science 134(3489), pp. 1501-1506.

McCauley, R. N. (2009). "Time is of the essence: Explanatory pluralism and accommodating theories about long-term processes." Philosophical Psychology 22, pp. 611-635.

McCauley, R. N., \& Bechtel,W.(2001). "Explanatory pluralism and heuristic identity theory." Theory \& Psychology 11(6), pp. 736-76o. https://doi.org/10.1177/0959354301116oo2.

Mesoudi, A. (2016). "Cultural evolution: A review of theory, findings and controversies." Evolutionary Biology 43(4), pp. 481-497. https://doi.org/10.1007/s11692-015-9320-0.

Mitchell, S. D. (2009). Unsimple Truths: Science, Complexity, and Policy. Chicago, London: The University of Chicago Press.

Munson, J., Amati, V., Collard, M., \& Macri, M. J. (2014). “Classic Maya bloodletting and the cultural evolution of religious rituals: Quantifying patterns of variation in hieroglyphic texts.” PloS One 9(9), e107982. https://doi.org/10.1371/journal.pone.0107982.

Nielbo, K. L., Braxton, D. M., \& Upal, A. (2012). "Computing religion: A new tool in the multilevel analysis of religion." Method \& Theory in the Study of Religion 24(3), pp. 267-29o. https://doi.org/10.1163/157006812X635709.

Norenzayan, A. (2016). “Theodiversity." Annual Review of Psychology 67(1), pp. 465-488. https://doi.org/10.1146/annurev-psych-122414-033426.

Norenzayan, A., Shariff, A. F., Gervais, W. M., Willard, A. K., McNamara, R., Slingerland, E., \& Henrich, J. (2016). "The cultural evolution of prosocial religions." Behavioral and Brain Sciences 39(e1), pp. 1-65. https://doi.org/10.1017/So140525X14001356.

Ojo, O. (2008). "Beyond diversity: Women, scarification, and Yoruba identity." History in Africa 35, pp. 347-374.

Otto, R. (1936). The Idea of the Holy. London: Oxford University Press.

Petersen, A. K. (2019). "Continuity as a core concept for a renewed scientific study of religion.” In A. K. Petersen, I. S. Gilhus, L. H. Martin, J. S. Jensen, \& J. Soerensen, eds., Evolution, Cognition, and the History of Religion: a New Synthesis. Leiden, Boston: Brill, pp. 81-99.

Petersen, A. K., Gilhus, I. S., Martin, L. H., Jensen, J. S., \& Soerensen, J., eds. (2019). Evolution, Cognition, and the History of Religion: a New Synthesis. Leiden, Boston: Brill.

Pineda, A., \& Bonifacio-Ramolete, A. (2008). "Cutud's ritual of nailing on the cross: Performance of pain and suffering." Asian Theatre Journal 25(1), pp. 58-76.

Pounder, D. J. (1983). "Ritual mutilation. Subincision of the penis among Australian Aborigines." The American Journal of Forensic Medicine and Pathology 4(3), pp. 227-229. 
Power, E. A. (2016). "Discerning devotion: Testing the signaling theory of religion." Evolution and Human Behavior 38(1), pp. 82-91. https://doi.org/10.1016/j.evolhumbehav .2016.07.003.

Purzycki, B. G., Apicella, C., Atkinson, Q. D., Cohen, E., McNamara, R. A., Willard, A. K., ... Henrich, J. (2016). "Moralistic gods, supernatural punishment and the expansion of human sociality." Nature 530(7590), pp. 327-330. https://doi.org/10.1038/nature16980.

Purzycki, B. G., Henrich, J., Apicella, C., Atkinson, Q. D., Baimel, A., Cohen, E., ... Norenzayan, A. (2018). "The evolution of religion and morality: a synthesis of ethnographic and experimental evidence from eight societies." Religion, Brain \& Behavior 8(2), pp. 101-132. https://doi.org/10.1080/2153599X.2016.1267027.

Rappaport, R. (1999). Ritual and Religion in the Making of Humanity. Cambridge: Cambridge University Press. https://doi.org/10.1017/CBO9780511814686.

Rappaport, R. (2000). Pigs for the Ancestors: Ritual in the Ecology of a New Guinea People. Waveland Press.

Richerson, P.J., \& Boyd, R. (2005). Not by Genes Alone: How Culture Transformed Human Evolution. Chicago, London: The University of Chicago Press.

Schjoedt, U. (2009). "The religious brain: A general introduction to the experimental neuroscience of religion." Method \& Theory in the Study of Religion 21(3), pp. 310-339. https://doi.org/10.1163/157006809X460347.

Schjoedt, U., Stødkilde-Jørgensen, H., Geertz, A. W., \& Roepstorff, A. (2009). "Highly religious participants recruit areas of social cognition in personal prayer." Social Cognitive and Affective Neuroscience 4(2), pp. 199-207. https://doi.org/10.1093/scan/ nsno5o.

Sears, D. O. (1986). "College sophomores in the laboratory: Influences of a narrow data base on social psychology' s view of human nature." Journal of Personality and Social Psychology 51(3), pp. 515-530. https://doi.org/10.1037//0022-3514.51.3.515.

Shaver, J. H., DiVietro, S., Lang, M., \& Sosis, R. (2018). "Costs do not explain variance in trust among secular groups." Journal of Cognition and Culture 18(1-2), pp. 180-204. https://doi.org/10.1163/15685373-12340025.

Shaver, J. H., Lang, M., Krátký, J., Klocová, E. K., Kundt, R., \& Xygalatas, D. (2018). “The boundaries of trust: Cross-religious and cross-ethnic field experiments in Mauritius." Evolutionary Psychology 16(4), pp. 1-15. https://doi.org/10.1177/1474704918817644.

Shweder, R. (2011). "The metaphysical realities of the unphysical sciences: Or why vertical integration seems unrealistic to ontological pluralists." In: E. Slingerland \& M. Collard eds., Creating Consilience: Integrating the Sciences and the Humanities. Oxford: Oxford University Press, pp. 56-73. https://doi.org/10.1093/acprof.

Slingerland, E. (2008a). What Science Offers the Humanities: Inegrating Body and Culture. Cambridge: Cambridge University Press. https://doi.org/10.1017/CBO97811 07415324.004. 
Slingerland, E. (2008b). "Who's afraid of reductionism? The study of religion in the age of cognitive science." Journal of the American Academy of Religion 76(2), pp. 375-411. https://doi.org/10.1093/jaarel/lfnoo4.

Slingerland, E., \& Bulbulia, J. (2011). "Evolutionary science and the study of religion." Religion 41(3), pp. 307-328. https://doi.org/10.1080/0048721X.2011.604513.

Slingerland, E., \& Collard, M. (2011). "Creating consilience: Toward a second wave." In: E. Slingerland \& M. Collard, eds., Creating Consilience: Integrating the Sciences and the Humanities. Oxford: Oxford University Press, pp. 3-42. https://doi.org/10.1093/ acprof.

Slingerland, E., \& Sullivan, B. (2017). "Durkheim with data: The Database of Religious History." Journal of the American Academy of Religion 85(2), pp. 312-347. https://doi .org/10.1093/jaarel/lfwo12.

Smaldino, P. E. (2017). "Models are stupid, and we need more of them." In: R. Vallacher, ed., Computation Social Psychology. Taylor \& Francis, pp. 311-331.

Smart, N. (1996). Dimensions of the Sacred: An Anatomy of the World's Beliefs. Berkley, Los Angeles: University of California Press.

Smith, E. A., Borgerhoff Mulder, M., \& Hill, K. (2000). "Evolutionary analyses of human behaviour: A commentary on Daly \& Wilson." Animal Behaviour 6o, pp. F21-F26. https://doi.org/10.1006/anbe.2000.1478.

Smith, E. A., \& Winterhalder, B., eds. (1992a). Evolutionary Ecology and Human Behavior. New Jersey: Transaction Publishers.

Smith, E. A., \& Winterhalder, B. (1992b). "Natural selection and decision-making: Some fundamental principles." In: E. A. Smith, \& B. Winterhlader, B., eds., Evolutionary Ecology and Human Behavior. New Jersey: Transaction Publishers, pp. 25-6o.

Smith, J. Z. (1991). Map is not Territory: Studies in the History of Religions. Chicago, London: The University of Chicago Press.

Snow, C. P. (1961). The Two Cultures and the Scientific Revolution. New York: Cambridge University Press. https://doi.org/10.1001/jama.1961.03040110091040.

Sosis, R. (2003). "Why aren't we all hutterites? Costly signaling theory and religious behavior." Human Nature 14(2), pp. 91-127.

Sosis, R. (2017). "Religions as complex adaptive systems." In: N. Clements, ed., Religion: Mental Religion. Farmington Hills, MI: Macmillan Reference USA, pp. 219-236.

Sosis, R. (2019a). "The building blocks of religious systems: Approaching religion as a complex adaptive system." In: G. Gorgiev, J. M. Smart, C. L. Flores Martines, \& M. Price, eds., Evolution, Development \& Complexity: Multiscale Models of Complex Adaptive Systems. Springer International Publishing, pp. 421-449.

Sosis, R. (2019b). "Why cultural evolutionary models of religion need a systemic approach." In: A. K. Petersen, I. S. Gilhus, L. H. Martin, J. S. Jensen, \& J. Soerensen, eds., Evolution, Cognition, and the History of Religion: a New Synthesis. Leiden, Boston: Brill, pp. 45-61. 
Sosis, R., \& Bressler, E. R. (2003). "Cooperation and commune longevity: A test of the costly signaling theory of religion." Cross-Cultural Research 37(2), pp. 211-239. https://doi.org/10.1177/1069397103251426.

Sosis, R., \& Bulbulia, J. (2011). "The behavioral ecology of religion: The benefits and costs of one evolutionary approach." Religion 41(3), pp. 341-362. https://doi.org/10 .1080/0048721X.2011.604514.

Sosis, R., \& Handwerker, W. P. (2011). "Psalms and coping with uncertainty: Religious Israeli women's responses to the 2006 Lebanon war." American Anthropologist 113(1), pp. 40-55. https://doi.org/10.1111/j.1548-1433.2010.01305.x.

Sosis, R., Kress, H. C., \& Boster, J. S. (2007). "Scars for war: Evaluating alternative signaling explanations for cross-cultural variance in ritual costs." Evolution and Human Behavior 28(4), pp. 234-247. https://doi.org/10.1016/j.evolhumbehav.2007. 02.007 .

Sosis, R., \& Ruffle, B. J. (2003). "Religious ritual and cooperation: Testing for a relationship on Israeli religious and secular kibbutzim." Current Anthropology 44(5), pp. 713722. https://doi.org/10.1086/37926o.

Stark, R. (1997). The Rise of Christianity: How the Obscure, Marginal Jesus Movement Became the Dominant Religious Force in the Western World in a Few Centuries. San Franciso: Harper Collins Publishers.

Tarr, B., Launay, J., \& Dunbar, R. I. M. (2016). Silent disco: Dancing in synchrony leads to elevated pain thresholds and social closeness. Evolution and Human Behavior 37(5), pp. 343-349. https://doi.org/10.1016/j.evolhumbehav.2016.02.004.

Taves, A. (2010). No field is an island: Fostering collaboration between the academic study of religion and the sciences. Method \& Theory in the Study of Religion 22(2), pp. 170-188. https://doi.org/10.1163/157006810X512356.

Taves, A. (2011). Religious Experience Reconsidered: A Building-Block Approach to the Study of Religion and Other Special Things. Princeton, Oxford: Princeton University Press.

Tinbergen, N. (1963). On aims and methods of ethology. Zeitschrift Für Tierpsychologie 20, pp. 410-433. Retrieved from http://onlinelibrary.wiley.com/doi/10.1111/ j.1439-0310.1963.tbo1161.x/abstract.

Tooby, J., \& Cosmides, L. (1990). The past explains the present. Emotional adaptations and the structure of ancestral environments. Ethology and Sociobiology 11(4-5), pp. 375-424. https://doi.org/10.1016/0162-3095(90)90017-Z.

Tooby, J., \& Cosmides, L. (1992). The psychological foundations of culture. In: J. Barkow, L. Cosmides, \& J. Tooby, eds., The Adapted Mind: Evolutionary Psychology and the Generation of Culture. Oxford: Oxford University Press, pp. 19-136. https://doi .org/10.4324/9781410608994.

Trivers, R. L. (1971). The evolution of reciprocal altruism. Quarterly Review of Biology 46(1), pp. 35-57. https://doi.org/10.1086/406755. 
Tylor, E. (1871). Primitive Culture: Researches into the Development of Mythology, Philosophy, Religion, Art, and Custom. London: John Murray.

Watts, J., Greenhill, S. J., Atkinson, Q. D., Currie, T. E., Bulbulia, J., \& Gray, R. D. (2015). Broad supernatural punishment but not moralizing high gods precede the evolution of political complexity in Austronesia. Proceedings of the Royal Society B 282, pp. 1-7. https://doi.org/10.1098/rspb.2014.2556.

Watts, J., Sheehan, O., Greenhill, S. J., Gomes-Ng, S., Atkinson, Q. D., Bulbulia, J., \& Gray, R. D. (2015). Pulotu: Database of Austronesian supernatural beliefs and practices. PLoS ONE 10(9), pp. 1-17. https://doi.org/10.1371/journal.pone.0136783.

Whitehouse, H., Jong, J., Buhrmester, M. D., Gómez, Á., Bastian, B., Kavanagh, C. M., ... Gavrilets, S. (2017). The evolution of extreme cooperation via shared dysphoric experiences. Scientific Reports 7, p. 44292. https://doi.org/10.1038/srep44292.

Whiten, A., Ayala, F. J., Feldman, M. W., \& Laland, K. N. (2017). The extension of biology through culture. Proceedings of the National Academy of Sciences 114(30), pp. 77757781. https://doi.org/10.1073/pnas.1707630114.

Wiebe, D. (2019). An old methodenstreit made new: Rejecting a 'science-lite' study of religion. In: A. K. Petersen, I. S. Gilhus, L. H. Martin, J. S. Jensen, \& J. Soerensen, eds., Evolution, Cognition, and the History of Religion: A New Synthesis. Leiden, Boston: Brill, pp. 130-140.

Willford, A. (2002). "Weapons of the meek": Ecstatic ritualism and strategic ecumenism among Tamil Hindus in Malaysia. Identities 9(2), pp. 247-28o. https://doi .org/10.1080/10702890212203.

Williamson, S. H., Hubisz, M. J., Clark, A. G., Payseur, B. A., Bustamante, C. D., \& Nielsen, R. (2007). Localizing recent adaptive evolution in the human genome. PLoS Genetics 3(6), pp. 0901-0915. https://doi.org/10.1371/journal.pgen.o03009o.

Wilson, E. O. (1998). Conscielience: The Unity of Knowledge. New York: Vintage Books. https://doi.org/10.1038/143391ao.

Xygalatas, D., Khan, S., Lang, M., Kundt, R., Kundtová Klocová, E., Krátký, J., \& Shaver, J.H. (In Press). Effects of extreme ritual practices on psychophysiological wellbeing. Current Anthropology.

Xygalatas, D., Mitkidis, P., Fischer, R., Reddish, P., Skewes, J., Geertz, A. W., ... Bulbulia, J. (2013). Extreme rituals promote prosociality. Psychological Science 24(8), pp. 1602-5. https://doi.org/10.1177/0956797612472910.

Zahavi, A. (1975). Mate selection-a selection for a handicap. Journal of Theoretical Biology 53(1), pp. 205-14. 